\title{
Planning woody biomass supply in hot systems under variable chips energy content
}

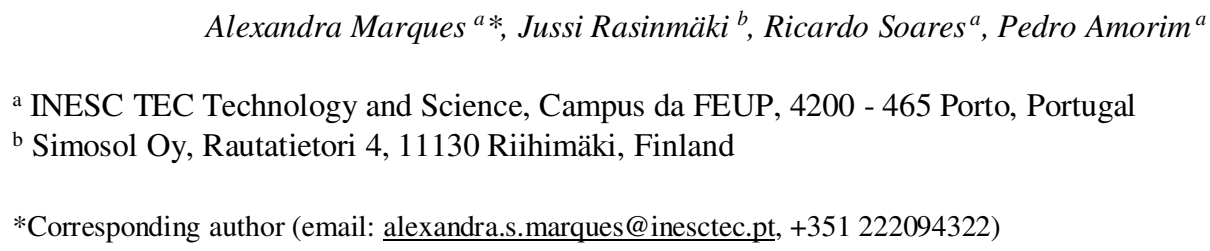

\begin{abstract}
:
The growing economic importance of the biomass-for-bioenergy in Europe motivates research on biomass supply chain design and planning. The temporally and geographically fragmented availability of woody biomass makes it particularly relevant to find cost-effective solutions for biomass production, storage and transportation up to the consumption facility. This paper addresses tactical decisions related with optimal allocation of wood chips from forest residues at forest sites to terminals and power plants. The emphasis is on a "hot-system" with synchronized chipping and chips transportation at the roadside. Thus, decisions related with the assignment of chippers to forest sites are also considered. We extend existing studies by considering the impact of the wood chips energy content variation in the logistics planning. This is a key issue in biomass-forbioenergy supply chains. The higher the moisture content of wood chips, the lower its net caloric value and therefore, a larger amount of chips is needed to meet the contracted demand. We propose a Mixed Integer Programming (MIP) model to solve this problem to optimality. Results of applying the model in a biomass supply chain case in Finland are presented. Results suggest that a 5\% improvement in the supplier profit can be obtained with the proposed approach when compared with a baseline situation that relies on empirical estimates for a fixed and known moisture content in the end of an obliged storage age.
\end{abstract}

Keywords: biomass supply chain planning; forest residues; synchronization of chipping and transportation; moisture content; energy content; mathematical programming

\section{Highlights:}

- Tactical biomass supply planning with synchronization of chipping and transport

- Chips energy content variation along the time in storage is acknowledged.

- Mathematical programming model optimally solved in case study of a finish company.

\section{Introduction}

Design and planning of biomass-for-energy supply chains (BESC) has been widely studied, as society reinforces the major role of biomass as a global primary energy source. In the case of woody biomass (produced from branches and other by-products of forestry operations), as in other forms of biomass (e.g. residues from agriculture, forestry, fisheries and municipal waste), the availability is temporally and geographically fragmented, which makes it particularly relevant to find cost-effective solutions for biomass production, storage and transportation up to the consumption facility (e.g. (Gold and Seuring 2011)). 
In this paper, the company in focus is a biomass supplier that buys the forest residues from forest owners (suppliers) and delivers the wood chips to power plants (customers) in order to meet their contracted demand of energy content, expressed in terms of MWh. The sequence of operations that are responsibility of the company are: 1) Logging, ie., tree felling, delimbing the trunk and cross-cutting into pre-defined lengths with specialized harvesters or manual harvesting with chainsaws; 2) Forwarding the logs and residues with skidders, forwarders or other types of tractors from the logging site up to pre-defined stacking locations at the roadside; 3) Chipping forest residues into smaller size wood chips, with specialized chippers located at the roadside or in terminals for longer term storage; 4) Transporting forest residues or wood chips by truck from the forest sites; and finally 5) Temporary storing and drying the residues and/or chips at the roadside or in terminals. Drying usually occurs under favorable sun and wind open-air conditions, but technical drying systems can be used in terminals, with addition of heat and with forced ventilation in order to reach much lower moisture content levels.

This research focus on planning chipping, transportation and storage operations, especially during the heating season when the power plants are operating. The emphasis is on "hot systems" where wood chipping and transportation operations are synchronized at the roadside. In this case, the trailer-mounted chipper feeds directly a chargeable container mounted in the truck, which will transport the chips ultimately to the plants. The company main decisions with respect to chipping are: 1) when and where to produce the wood chips, to match wood chips availability and plants demand; 2) which chipper to assign to forest residues piles at the forest site. Main decisions with respect to transportation are: 1) amounts from where, to where, when, what product (flows); 2) transportation capacity needed in each period. In respect to storage, the company main decision is: 3) how long to store/dry forest residues/wood chips and where (roadside or terminals)? It is noteworthy that, in case of hot systems, there is no intermediate storage of wood chips between these operations, but there is usually storage of forest residues at the logging sites because chipping is done some time after harvesting. Contrarily, the "cold system" encompasses the transport of forest residues to the terminals for later chipping and storage (e.g. (Eriksson 2016)).

The literature shows several examples of mathematical programming techniques to help plan chipping and transportation operations with the aim to minimize the cost per $\mathrm{kWh}$ generated (e.g. (Shabani, Akhtari, and Sowlati 2013) (De Meyer et al. 2014), (Atashbar, Labadie, and Prins 2016)). Previous research from (Gunnarsson, Rönnqvist, and Lundgren 2004) addressed the case of a large Swedish biomass-supplying entrepreneur. They developed a model to decide when and where forest residues have to be converted into chips, transported and stored in order to satisfy the contracted demand at the sawmill at a minimum cost. They assume that harvesting (and chipping) in each stand occurs in a single period and do not address the assignment of machinery to these operations. Continuous variables determine biomass flows from harvest sites and sawmills to heating plants in each time period and binary variables determine whether forest residues are forwarded or chipped, whether a sawmill has been contracted and a terminal is used in a certain time period (one month) over a planning horizon of one year. The problem was solved with a heuristic approach and applied in six scenarios of possible variations in the supply chain design. In a similar context, (Flisberg, Frisk, and Rönnqvist 2012) apply a MIP model to the optimization of inventory planning at the terminals in order to support 
the choice of chipping technology and location and the route to the heating plants. The model was implemented in a Decision Support Tool called FuelOpt. (Kanzian et al. 2009) and (Gronalt and Rauch 2007) also studied the biomass supply in case studies in Austria. The former proposed a Linear Programing model while the latter applies a simple stepwise heuristic approach based on the calculation of available regional forest fuel potential.

Despite these relevant efforts, the dependency between chipping and transportation operations that characterize "hot systems" is still poorly addressed. Previous research (e.g. (Eriksson 2016), (Eriksson, Eliasson, and Jirjis 2014), (Karttunen et al. 2012)) develop simulation-based approaches to assess productivity issues related with alternative chipping systems as well as to show the importance of balancing chipping and transportation capacity to avoid unnecessary costs related with the trucks waiting time and chippers idle time. In a case similar to this, (Asikainen 2010) proposes a discreteevent simulation model to find optimal set-ups for the supply chain of crushed material, made from stumps at different road transport distances. Yet, optimization models for jointly planning chipping and transportation remain undone.

Moreover, the impact of wood chips moisture in storage and logistics planning is not yet properly addressed, although it is a key aspect of the business. Usually companies use the chips with lower moisture content as possible, because this corresponds to a higher energy content, meaning that less energy is spent to vapor the water in the wood instead of heating. Moisture content also affects negatively the efficiency of combustion (higher emissions of carbon monoxide, hydrocarbon and fine particles), increases the risk of decay during storage, and increases the transportation costs (Lopez 2012). Chips moisture content is higher just after harvesting and tends to decrease along the time spent in storage (e.g. (Hofmann et al. 2017), (Holdrich and Hartmann 2006), (Nurmi 1999). Yet, the drying rate depends on the initial moisture content, the weather conditions (specially sun and wind) during the drying period, the drying capacity of the wood, phytosanitary conditions, pile cover type and arrangement, and other features of the storage yard (e.g. dimension, soil drainage capacity) (Lopez 2012).

One of the few studies addressing the impact of moisture content variation in logistics planning was done by (Dunnett, Adjiman, and Shah 2007). They apply a simulation model built with a state-task-network approach. Another study by (Shabani and Sowlati 2016) proposes a 'stochastic programming-robust optimization' model to tackle biomass supply planning, addressing uncertainty in biomass quality and biomass availability. Nevertheless, existing planning models for biomass supply fail to effectively capture the impact of the changes in the product properties according to storage time, and do not incorporate the storage age into the model

The main contributions of this paper are to formulate and solve the tactical biomass supply planning problem, thus extending the work of (Gunnarsson, Rönnqvist, and Lundgren 2004; Flisberg, Frisk, and Rönnqvist 2012) by explicitly considering the variation in chips energy content (or moisture content) over time in storage. Furthermore, it addresses the dependency between chipping and transportation at the roadside that characterize the "hot systems" as well as the space-time continuity of chipping operations. 
The remainder of this paper is as follows. Chapter 2 presents the problem description, with emphasis on identifying the impact of the variation of the wood chips energy content in the logistics planning as well as explaining the dependencies between chipping and transportation operations that characterize the hot systems. Chapter 3 presents the proposed modelling approach. It further discusses possible variations to the general Mixed-Integer Programming model for cases where the storage age is not dealt with or the movements of the chippers between piles can be simplified. Chapter 4 presents the computational experiments for a case study of a biomass supply company in Finland. Finally, chapter 5 presents the concluding remarks.

\section{Problem description}

The woody biomass supply planning problem in hot systems under variable chips energy content can be formulated as follows. Considering a set of power plants $(M)$ with a given demand of energy content (MWh) per week, the problem consists in determine 1) which piles $(P)$ of forest residues should be chipped according to its availability and moisture content; 2) by which chippers $(K)$, and 3 ) where to transport the chips, considering the possibility to use forest sites and terminals $(O)$ for temporary storage (Figure 1 ). The objective is to maximize the operational net profit, considering the revenue from wood chips sales to the plants as well as the costs of chipping, transportation and storage. This is a multi-period flow problem, where the planning periods be half-a-day, one day or even week, and the planning horizon can range from 1 to up to 6 months, the latter corresponding to the expected duration of the heating season, when the power plants are operating.

$<$ figure 1 here $>$

\subsection{Incorporating wood chips energy content variation in logistics planning}

The energy demand at the power plants is specified in MWh. This corresponds to the minimum supply during the entire cold season, when the plant is operating, while the maximum supply can be approximated by the plants processing capacity. The price per MWh vary from plant to plant and the supplier was no control over pricing, which is assumed to be fixed within the planning horizon. Depending on the type of boilers installed, some plants also define thresholds in respect to the minimum energy content accepted. But in general, the larger the plant the more tolerant it is to variations in the fuel properties.

Forest residues and wood chips availability is specified in bulk $\mathrm{m}^{3}$. This is the unit of measurement for small pieces of loose wood (e.g. wood chips, sawdust, wood pieces) that attain a total volume of one cubic meter including air gaps (Krajnc 2015). 1 bulk m$^{3}$ wood chips corresponds to $0.33 \mathrm{~m}^{3}$ round wood equivalent. The piles of forest residues become available at the roadside since the period when harvesting occurred, which is known beforehand. Also the amount of forest residues available in each pile is known and is usually estimated as a percentage of the total stand volume, which can be predicted with yield and growth models based on forest inventory data.

The conversion MWh to $\mathrm{m}^{3}$ is the wood chips energy content or its net caloric value or net heating value $(\epsilon)$. It corresponds to the usable heating volume released in complete 
burning of a specific volume of fuel, after subtracting the heat of vaporization of the water vapor (2.44 MJ per kg of water). It is computed mainly as a function of the moisture content $(\vartheta)$ (Equation 1); other parameters are the net caloric value of oven-dry wood $\left(\epsilon_{0}\right)(18.5 \mathrm{MJ} / \mathrm{kg})$ and bulk density $(\rho)\left(\mathrm{kg} / \mathrm{bulk}^{3}\right)$, whose values for the main tree species and moisture content can be found in the Wood Fuels Handbook (Krajnc 2015):

$$
\epsilon=\left(\frac{\epsilon_{0}(100-\vartheta)-2.44 \vartheta}{100}\right) 0.278 \cdot \rho \quad\left(\mathrm{KWh} / \mathrm{m}^{3}\right)
$$

Consequently, the wood chips moisture content is the key parameter for the business. The higher the moisture content the higher the volume necessary to mee the demand. Thus, it is measured often in the course of biomass supply processes with portable measuring devices. The wood moisture content (or water content, or moisture content percentage on green basis $(\vartheta)$ ) is the mass of water present in relation to the mass of fresh wood. $\vartheta=\frac{W_{w}-W_{0}}{W_{w}} \times 100$, where $W_{w}$ is the wet weight of wood and $W_{0}$ is the oven-dry weight of wood. Note that some portable devices may measure the wood humidity (or moisture content on oven-dry basis $(\theta)$ ), corresponding to the ratio between the mass of water present and the mass of oven-dry wood. In those situations the following conversion formula can be used $\vartheta=\frac{100 \theta}{100+\theta}$. As rules of thumb in the literature (e.g. (Krajnc 2015)), newly-chopped fresh wood has half of water and half of wood substance $(\theta=100 \%, \vartheta=50 \%)$. Fresh wood chips have $\vartheta$ between $45 \%$ and $55 \%$. After drying for a couple of months under favorable open air conditions it lowers to $25-40 \%$, while in case of technical drying can reach below 20\%. (Lopez 2012) and (Francescato and Antonini 2008). According to (Krajnc 2015), the net caloric value of wood chips is around $3.4 \mathrm{KWh} / \mathrm{kg}$ (or $\mathrm{MWh} /$ ton).

The variation of moisture content of forest residues/wood chips along the time spent in open-air drying at the forest sites or terminals can be estimated by means of local field tests, drying curves or mathematical models or even other alternative empirical approaches. Experimental field tests help to determine the key factors impacting in the drying process (e.g. (Nurmi 1999), (Pettersson and Nordfjell 2007), (Casal et al. 2010)). As an example, (Hofmann et al. 2017) concluded that the key impacting factors in spruce piles (forest residues and wood chips) in Central European conditions are season, storage duration, assortment and fleece cover. In winter period (November to April), wood chips moisture content varied from $56 \%$ to $53 \%$ (average of $0,15 \%$ per week), while in summer (May to October) varied from $48 \%$ to $34 \%$ (average of $0,7 \%$ per week). Forest residues dried faster than chips. Piles covered with fleece also dried much faster due to heat accumulation and lower heat dissipation.

Graphical drying curves help to predict the expected moisture content along the time spent drying under case-specific conditions (e.g. (Lenz et al. 2015). As an example, (Holdrich and Hartmann 2006) proposed drying curves for spruce and beech piles in central European conditions, starting in the winter season. The maximum moisture content is reached in the beginning of the storage period and then decreases during the year until reaching the minimum moisture in summer. After this period, the wood moisture content may increase again due to rain and increased air humidity. Existing mathematical models usually predict change in moisture content as a function of mean air temperature and relative moisture. Still other studies propose more general mathematical models that predict moisture content change as a function of mean air temperature and relative moisture (e.g. (Erber, Kanzian, and Stampfer 2012), (Simpson and Tschernitz 1979)). 
This research considers all these methods equally valid and can be adopted by the biomass company for the purpose of biomass supply planning at the tactical level. If fact, this research is built under two main assumptions: 1) Existing stock (and moisture content) at the beginning of the planning period is known; 2) The variation of moisture content along the time spent in storage is also known in advance for each storage location (piles and terminals), by means of local field tests, drying curves or mathematical models or even other alternative empirical approaches.

In cases where no mathematical model is available, a generic logistic function can be used (see Equation 2) where $\alpha>0$ is a parameter that defines the sigmoid curve's steepness, $\pi$ sets the sigmoid curve's midpoint in the $t$ axis, $\vartheta_{0}$ is the initially measured wood moisture content and $\vartheta_{\text {eq }}$ is the curve's horizontal lower asymptote and may be estimated by the lowest moisture content measured in a one-year period. As an example, for the spruce piles stored in Freising, Germany during 2 consecutive years (Dec. 2002 to Nov. 2004) presented in (Holdrich and Hartmann 2006), $\alpha=0.9$ and $\pi=4.6$.

$$
\vartheta(t)=\vartheta_{\mathrm{eq}}+\frac{\vartheta_{0}-\vartheta_{\mathrm{eq}}}{1+e^{\alpha(t-\pi)}}
$$

\subsection{Addressing the dependency between chipping and transport at the roadside (hot system) in biomass supply planning}

Chipping and transportation operations have a start-to-start dependency, meaning that both need to be present and available at the roadside so that both operations can be performed. Similarly, there is a finish-to-finish dependency. This is because forest residues are chipped directly into the trucks' container and transported just after the container is full (i.e. in the same period). Consequently, biomass supply planning should seek for an optimal balance between productivity/capacity of chippers and trucks, in order to avoid unnecessary costs related with the trucks waiting time and chippers idle time.

There are other relevant business rules related with chipping that need to be taken into account for biomass supply planning. The first is that the chipper processes one pile at a time. The chipper productivity in terms of $\mathrm{m}^{3} /$ hour depends on the type of chipper and the pile characteristics (e.g. size of the wood fuels) (Krajnc 2015). Low power chippers (engine $\sim 50 \mathrm{~kW}$ ), usually installed on the rear three point hitch of a tractor or on a trailer, only processing small diameters (up to $20 \mathrm{~cm}$ ) and chipping productivity below 10 bulk $\mathrm{m}^{3}$ of wood chips per hour; medium power chippers (engine $50-110 \mathrm{~kW}$ ), usually trailermounted, can chip diameters up to $30 \mathrm{~cm}$ and the chipping productivity is up to 50 bulk $\mathrm{m}^{3}$ of wood chips per hour; high power chippers (engine $>110 \mathrm{~kW}$ ) installed in trailers or trucks, can chip large diameters $(>30 \mathrm{~cm})$ and produce more than $100 \mathrm{bulk} \mathrm{m}^{3}$ of wood chips per hour. Once chipping starts (and a truck is available) the productivity is assumed constant for that chipper in that pile. There is a daily cost of having a chipper assigned to a pile and a hourly utilization cost, that varies according to the type of equipment and ownership but it is the same either it is working or paused because no truck is available for loading. Hourly costs are higher when chipping occurs beyond the number of working hours of a regular shift. It is not mandatory that all piles are chipped within the time horizon.

Other important aspects that condition the assignment of chippers to piles are here called space-time continuity constraints. Temporal continuity means that the chipper remains 
in a pile until all the material is transported. Consequently, chipping may extend over several consecutive time periods. This is the same as saying that chipping operations cannot be interrupted once started, known in the production scheduling literature as a nonpreemptive requirement (e.g (Jaramillo and Erkoc 2017)). Spatial continuity relates to the fact that for trailer-mounted chippers, there is a second type of truck needed to move the chipper to and from the pile, with extra operational costs. Consequently, chippers should be moved to a nearby pile to avoiding unnecessary chipper's transportation costs (and unproductive time).

In respect to transportation, this research assumes that there is an homogenous fleet of available trucks, with a coupled trailer with sidewalls or container. The loading capacity of each truck is around 87 bulk m3 (21ton). Trucks' usage cost also varies with ownership. The supplier preferably uses their own chipper and trucks. If the company does not have enough chippers and/or trucks to comply with the power plants' energy demands, then the company is able to subcontract chippers.

\section{Problem modelling}

The proposed modelling approach for the biomass supply chain problem builds on the MIP model developed by (Gunnarsson, Rönnqvist, and Lundgren 2004) and extends it according to the problem description. The assignment variables are extended to address hot systems. $x_{k p t}$ take value 1 if chipping and transportation operations will occur in pile $p$ in period $t$ by chipper $k$, and 0 otherwise. As in (Gunnarsson, Rönnqvist, and Lundgren 2004), continuous variables represent the biomass flows. The linking constraints between the assignment variables and the flow variables assure that flow only exists if and when the operations are performed, therefore implementing the dependency between chipping and transportation that characterize the hot systems.

New auxiliary binary variables are added for modelling the space-time continuity constraints. $z_{k p_{1} p_{2} t}$ take value 1 if there is movement of chipper $k$ from to in the end of period t. In respect to spatial continuity, a feasible movement of the chipper between piles $p_{1}$ and $p_{2}$ requires that take value 1 if $=1$ and $=1$. Therefore, $\geq+-1$. For each pile it can happen at most once along the entire planning period $(\leq 1, \forall)$. To assure flow connectivity, it is necessary a new set of constraints that balance the inflows and the outflows for each pile-time period, as explained in 3.2. In respect to temporal continuity, the previous constraints are sufficient to force the chipper to remain in pile $p_{l}$ in consecutive periods whenever needed, because 1) the chipper either continues in that pile $p_{1}$ or moves to another pile $\left.p_{2}:(\in P \cup ; \neq) ; 2\right)$ can only move from $p_{1}$ to another pile $p_{2}$ once i.e. cannot came back to $p_{1}$ to complete the task and them move again from $\mathrm{p}_{1}$ with minimum costs (see figure 2).

$<$ figure 2 here $>$

New continuous decision variables account for machinery/crew total number of working hours, including the shift duration and the overtime work, i.e. beyond the regular working shift duration. There variables are instrumental for dealing with the pool of chippers with heterogeneous productivity in terms of $\mathrm{m}^{3} /$ hour. Additional continuous variables $h_{k p t}^{*}$ account for the amount of overtime chipping work. In cases where there is still some minor amounts left to chip in the end of a working shift in $t$, these variables are 
instrumental for modelling the trade-off between concluding chipping in that period $t$ with additional overtime costs or delaying operations to $t+1$ with additional costs related with the chipper daily utilization (see Figure 2).

The continuous variables representing biomass flows and stock need to be adapted to take into account the variation of moisture content according to the storage age. Previous work in logistics planning dealing with perishability in food goods (e.g. (Amorim, Costa, and Almada-Lobo 2014)) use decision variables $w_{u, t}^{e}$ to define the initial inventory of product $u$, with age $e$ available at period $t, a=0, \ldots \min \left\{a_{u}-1 ; t-1\right\}$, where $a_{u}$ is the shelf-life duration of product $u$, right after being produced. The inventory balance constraints account for the spoilage rate for each product. This research proposes a similar modelling approach that considers a set of moisture content classes $(e \in E)$. A set of continuous variables $f_{i j e t_{1} t_{2}}$ represent the amount of wood chips with moisture content class $e$ transported from supply point $i \in I$ to demand point $j \in J$ in period $t_{2} \in T$, that arrived to $i$ in period $t_{1} \in T^{\emptyset}:\left\{t \mid t \in T, t<t_{2}\right\}\left(\mathrm{m}^{3}\right)$. The period between $t_{1}$ and $t_{2}$ corresponds to the storing age. Similarly, variables $s_{o e t_{1} t_{2}}$ are the amount of wood chips with moisture class $e$ stored in supply point $o \in O$ in period $t_{2}$ that arrived in period $t_{1}$.

\subsection{Procedure for calculating moisture content variation}

In this framework, a procedure is needed to compute the variation of moisture content in forest residues/chips during the time in storage (at roadside piles and/or terminals), which can be generically represented with a drying curve (Figure 3 ).

$<$ figure 3 here $>$

Concerning storage in a roadside pile, for a given pile $p$ the time spent in storage corresponds to $t_{1}^{p}-t_{o}^{p}$, where $t_{1}^{p}$ is time period when residues/chips are transported from the pile to the terminal or to the plant; and $t_{o}^{p}$ is the time period since which the pile $\mathrm{p}$ is available (i.e., forest harvesting operations are concluded). The initial moisture content $\vartheta_{t_{0}}^{p}$ is measured in $t_{o}^{p}$ with an appropriate device (Assumption 1). The moisture content $\vartheta_{t_{1}}^{p}$ is estimated with the drying curve/mathematical model, which is assumed to be known (Assumption 2), as discussed in section 2.1. It is noteworthy that there can be multiple outflows from the same pile in different time periods (and for different destinations), generically represented in Figure 3 as $t_{1}^{p}, t_{1}^{p \prime}$.

In period $t_{1}^{p}$, the residues/chips transportation costs $(€ / \mathrm{m} 3)$ depend on unit transportation cost $\tau^{I}(€ / \mathrm{ton} / \mathrm{km})$, distance $(\mathrm{km})$ and the bulk density $\rho^{e}\left(\mathrm{~kg} / \mathrm{bulk} \mathrm{m}^{3}\right)$ (Equation 4$)$. The latter varies with the moisture content. The price of chips at the plant $(€ / \mathrm{MWh})$ also depends on its net caloric value $\epsilon^{e}\left(\mathrm{MWh} / \mathrm{m}^{3}\right)$, which is calculated as a function of the moisture content (Equation 1). Therefore, $\vartheta_{t_{1}}^{p}$ will take the average value of the corresponding class $e$, i.e. $\vartheta_{t_{1}}^{e p}=\bar{e}^{e}$. For implementation purposes, this can be generically represented by $\vartheta_{t}^{p}=\sum_{e \in E} \beta_{\text {pet }} \cdot \bar{e}^{e}$, where auxiliary binary parameters $\beta_{\text {pet }}$ take the value 1 when the moisture content class $e \in E$ is applied to $p \in P$ in period $t \in T$, and 0 otherwise. These parameters are pre-processed before running the model, for all possible combinations of $(p, e, t)$ and $\sum_{e \in E} \beta_{p e t}=1, \forall p, \forall e, \forall t$.

$$
\tau_{i j}=\tau^{I} \cdot d_{i j} \cdot \rho^{e}, \forall i \in I, \forall j \in J(4)
$$




\section{Sets}

$T \quad$ Set of planning periods, $T=\{0, \ldots,|T|-1\}$

$P \quad$ Set of piles of raw material at the roadside

$P^{b} \quad$ Set of piles of raw material at the roadside, including the depot $P^{b}=P \cup\{b\}$

$M \quad$ Set of power plants (mills)

$O$ Set of terminals (intermediate stockyards)

$I \quad$ Set of supply points, $I=P \cup O$

$J \quad$ Set of demand points, $J=M \cup O$

$K \quad$ Set of chipping machines/crews

E Set of classes of wood chips moisture content

\section{Parameters}

$a_{p} \quad$ Availability of wood chips in pile $p \in P\left(\mathrm{~m}^{3}\right)$ 


\begin{tabular}{|c|c|}
\hline$d_{m}$ & $\begin{array}{l}\text { Demand of energy content from wood chips at plant } m \in M(\mathrm{MWh}) \text { for the entire } \\
\text { planning period }\end{array}$ \\
\hline$c_{m}^{M}$ & Maximum throughput of wood chips at plant $m \in M(\mathrm{MWh})$ \\
\hline$c_{o}^{O}$ & Storage capacity in terminal $o \in O\left(\mathrm{~m}^{3}\right)$ \\
\hline$c^{V}$ & Transportation capacity of each truck $\left(10^{3} \mathrm{~kg}\right)$ \\
\hline$c_{k}^{K}$ & Unit cost of using chipper $\mathrm{k}(€)$ \\
\hline$N$ & Number of available trucks \\
\hline$r_{k p}$ & Productivity of chipper $k \in K$ in pile $p \in P\left(\mathrm{~m}^{3} / \mathrm{h}\right)$ \\
\hline$y_{k}^{m} ; y_{k} ; y_{k}^{*}$ & Minimum, regular and max. extra-hours working time of chipper/crew $k \in K$ (h) \\
\hline$\omega_{k p} ; \omega_{k p}^{*}$ & $\begin{array}{l}\text { Standard and Overtime hourly chipping cost of using chipper } k \in K \text { in pile } p \in P \\
(€ / h)\end{array}$ \\
\hline$\gamma_{o}$ & Unit storage cost of wood chips per period at terminal $o \in O\left(€ / \mathrm{m}^{3}\right)$ \\
\hline$\tau$ & Unit wood chips' transportation cost $(€ /$ ton $/ \mathrm{km})$ \\
\hline$\chi_{k}$ & Unit transportation cost of chipper $\mathrm{k}(€ / \mathrm{km})$ \\
\hline$d_{i j}$ & $\begin{array}{l}\text { Distance between the point of origin } i \text { (pile or terminal) and the point of } \\
\text { destination } j(\mathrm{~km})\end{array}$ \\
\hline$\vartheta_{t}^{p}$ & Moisture content of residues/chips in pile $p \in P(\%)$ in the period $t$ \\
\hline$t_{0}^{p}$ & Time period since which pile/depot $p \in P^{b}$ is available to be chipped \\
\hline$\rho_{e}$ & Bulk density of wood chips in energy class $e\left(10^{3} \mathrm{~kg} / \mathrm{m}^{3}\right)$ \\
\hline$\epsilon_{e}$ & Energy content per volume unit of wood chips in in energy class $e\left(\mathrm{MWh} / \mathrm{m}^{3}\right)$ \\
\hline$\varphi_{\text {em }}$ & Price paid energy content unit delivered to plant $m \in M(\epsilon / M W h)$ \\
\hline$\beta_{p e t}$ & $\begin{array}{l}\text { Auxiliary parameter that takes value } 1 \text { when the moisture content class } e \in E \text { is } \\
\text { applied to } p \in P \text { in period } t \in T ; 0 \text { otherwise }\left(\sum_{e \in E} \beta_{p e t}=1, \forall p, \forall e, \forall t\right) \text {. }\end{array}$ \\
\hline$\eta_{e_{1} e_{2} t_{1} t_{2}}^{o}$ & $\begin{array}{l}\text { Auxiliary parameter that takes value } 1 \text {, if chips arriving in terminal } o \in O \text { with } \\
\text { energy content scale } e_{1} \in E \text { in period } t_{1} \in T^{\varnothing}=\left\{t \mid t \in T, t<t_{2}\right\} \text {, are expected to be } \\
\text { in energy content scale } e_{2} \in E \text { in period } t_{2} \in T ; 0 \text {, otherwise }\left(\sum_{e_{2} \in E} \eta_{e_{1} e_{2} t_{1} t_{2}}^{o}=\right. \\
\left.1, \forall o,\left(e_{1}, t_{1}\right), t_{2}\right)\end{array}$ \\
\hline
\end{tabular}

383 Decision variables

$x_{k p t} \quad 1$, if chipping-transportation occur in pile $p \in P^{b}$ in period $t \in T$, with chipper $k \in K$; , otherwise

$f_{i j e t_{1} t_{2}} \quad$ Amount of wood chips with energy content $e$ transported from supply point $i \in I$ to demand point $j \in J$ in period $t_{2} \in T$ that arrived in period $t_{1} \in T^{\varnothing}=\left\{t \mid t \in T, t<t_{2}\right\}\left(\mathrm{m}^{3}\right)$

$S_{\text {oet }_{1} t_{2}} \quad$ Amount of wood chips stored at terminal $o \in O$ with energy content scale $e \in E$ in period $t_{2} \in T$ that arrived in period $t_{1} \in T^{\varnothing}=\left\{t \mid t \in T, t<t_{2}\right\}\left(\mathrm{m}^{3}\right)$

$h_{k p t} \quad$ Number of total hours used by machine/crew $k \in K$ in pile $p \in P$ in period $t \in T$ (h)

$h_{k p t}^{*} \quad$ Number of overtime hours used by machine/crew $k \in K$ in pile $p \in P$ in period $t \in T$ (h)

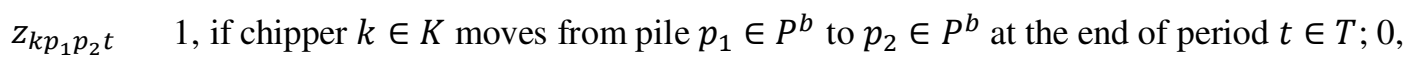
otherwise 


\section{Model [M1]}

$$
\begin{gathered}
\max \quad F=\sum_{i \in I} \sum_{m \in M} \sum_{e \in E} \sum_{t_{2} \in T} \sum_{t_{1} \in T^{\emptyset}} \varphi_{e m} \epsilon_{e} f_{\text {imet }_{1} t_{2}}- \\
-\sum_{k \in K} \sum_{p \in P} \sum_{t \in T} C_{k}^{K} x_{k p t}- \\
-\sum_{k \in K} \sum_{p \in P} \sum_{t \in T}\left[\omega_{k p}\left(h_{k p t}-h_{k p t}^{*}\right)+\omega_{k p}^{*} h_{k p t}^{*}\right]- \\
-\sum_{i \in I} \sum_{j \in J} \sum_{e \in E} \sum_{t_{1} \in T^{\varnothing}} \sum_{t_{2} \in T} \tau d_{i j} \rho_{e} f_{i j e t_{1} t_{2}}- \\
-\sum_{k \in K} \sum_{p_{1} \in P^{b}} \sum_{p_{2} \in P^{b}} \sum_{t \in T} \chi_{k} d_{p_{1} p_{2}} z_{k p_{1} p_{2} t}- \\
-\sum_{o \in O} \sum_{e \in E} \sum_{t_{1} \in T^{\varnothing}} \sum_{t_{2} \in T} \gamma_{o} \cdot s_{o e t_{1} t_{2}}-
\end{gathered}
$$

Subject to:

$$
\begin{aligned}
& d_{m} \leq \sum_{i \in I} \sum_{e \in E} \sum_{t_{1} \in T^{\varnothing}} \sum_{t_{2} \in T} \epsilon_{e} f_{\text {imet }_{1} t_{2}} \leq C_{m}^{M} \quad \forall m \in M \\
& \sum_{j \in J} \sum_{e \in E} \sum_{t_{1} \in T^{\emptyset}} \sum_{t_{2} \in T} f_{\text {pjet }_{1} t_{2}} \leq a_{p} \quad \forall p \in P \\
& x_{k p t} y_{k}^{m} \leq h_{k p t} \leq\left(y_{k}+y_{k}^{*}\right) x_{k p t} \quad \forall k \in K, \forall p \in P, \forall t \in T \\
& h_{k p t}-y_{k} \leq h_{k p t}^{*} \leq y_{k}^{*} \quad \forall k \in K, \forall p \in P, \forall t \in T \\
& \sum_{k \in K} h_{k p t_{2}} \cdot r_{k p}=\sum_{j \in J} \sum_{e \in E} \sum_{t_{1} \in T^{\varnothing}} f_{p j e t_{1} t_{2}} \quad \forall p \in P, \forall t_{2} \in T \\
& s_{\text {oet }_{2} t_{2}}=\sum_{p \in P} \sum_{t_{1} \in T^{\varnothing}} f_{\text {poet }_{1} t_{2}} \quad \forall o \in O, \forall e \in E, \forall t_{2} \in T \\
& s_{\text {oet }_{1} t_{2}}=s_{\text {oet }_{1}\left(t_{2}-1\right)}-\sum_{m \in M} \sum_{e^{\prime} \in E} \eta_{\text {oee }} t_{1} t_{2} f_{\text {ome }^{\prime} t_{1} t_{2}} \quad \begin{array}{c}
\forall o \in O, \forall e \in E, \\
\forall t_{1} \in\left\{t \mid t \in T, t_{1}<t_{2}\right\}, \forall t_{2} \in T
\end{array} \\
& \sum_{e \in E} \sum_{t_{1} \in T^{\emptyset}} s_{o e t_{1} t_{2}} \leq c_{o}^{o} \quad \forall o \in O, \forall t_{2} \in T \\
& \sum_{i \in I} \sum_{j \in J} \sum_{e \in E} \sum_{t_{1} \in T^{\varnothing}} \rho_{e} \cdot f_{\text {ijet }_{1} \mathrm{t}} \leq c^{V} N \quad \forall t \in T \\
& \sum_{p \in P^{b}} x_{k p t}=1 \quad \forall k \in K, \forall t \in T \\
& \begin{array}{cc}
z_{k p_{1} p_{2}(t-1)} \geq x_{k p_{1}(t-1)}+x_{k p_{2} t}-1 \quad \forall k \in K, \forall p_{1}, p_{2} \in P^{b}: p_{1} \neq p_{2}, \\
\forall t \in T \backslash\{0\}
\end{array} \\
& Z_{k p_{1} b(t-1)} \geq x_{k p_{1}(t-1)} \quad \forall k \in K, \forall p_{1} \in P, t=|T| \\
& x_{k p_{1} t}+\sum_{p_{2} \in P^{b}} z_{k p_{2} p_{1} t}=x_{k p_{1}(t+1)}+\sum_{p_{2} \in P^{b}} z_{k p_{1} p_{2} t} \quad \forall k \in K, \forall p_{1} \in P, \forall t \in T \\
& \sum_{k \in K} \sum_{p_{2} \in P^{b}} \sum_{t \in T} z_{k p_{1} p_{2} t} \leq 1 \quad \forall p_{1} \in P \\
& x_{k p t} \in\{0,1\} \quad \forall k \in K, \forall p \in P^{b}, \forall t \in T: t \geq t_{0}^{p}
\end{aligned}
$$




$$
\begin{gathered}
0 \leq f_{\text {pjet }_{1} t_{2}} \leq \beta_{p e t_{2}} a_{p} \\
0 \leq f_{\text {omet }_{1} t_{2}} \leq \sum_{p \in P: t_{1} \geq t_{0}^{p}} \sum_{e_{1} \in E} \beta_{p e_{1} t_{1}} \eta_{o e_{1} e t_{1} t_{2}} c_{o}^{O} \\
0 \leq s_{\text {oet } t_{2}} \leq \sum_{p \in P: t_{1} \geq t_{0}^{p}} \beta_{p e t_{1}} c_{o}^{O} \\
0 \leq h_{k p t} \leq y_{k}+y_{k}^{*} \\
0 \leq h_{k p t}^{*} \leq y_{k}^{*} \\
z_{k p_{1} p_{2} t} \in\{0,1\}
\end{gathered}
$$

$$
\begin{aligned}
& \forall p \in P, \forall j \in J, \forall e \in E, \forall t_{1}, t_{2} \in T: t_{1} \\
& =t_{0}^{p}, t_{2} \geq t_{1} \\
& \forall o \in O, \forall m \in M, \forall e \in E, \forall t_{1}, t_{2} \\
& \in T: t_{2}>t_{1} \\
& \forall o \in O, \forall e \in E, \forall t_{1}, t_{2} \in T: t_{1} \leq t_{2} \\
& \forall k \in K, \forall p \in P, \forall t \in T: t \geq t_{0}^{p} \\
& \forall k \in K, \forall p \in P, \forall t \in T: t \geq t_{0}^{p} \\
& \forall k \in K, \forall p_{1}, p_{2} \in P^{b}: p_{1} \neq p_{2}, \forall t \in \\
& T:\left\{t \geq t_{0}^{p_{1}}, t+1 \geq t_{0}^{p_{2}}\right\}
\end{aligned}
$$

The objective function maximizes the total profit of the biomass supplier, including the revenues from the sales of the wood chips delivered at the plants (5i) coming from the roadside piles or terminals; the daily cost of using each chipper (5ii); hourly costs of the roadside chipping operations, including the overtime work (5iii); wood chips' total transportation costs, including from the roadside to terminals or to plants and from terminals to plants (5iv); chippers' movement costs between piles (5v); and total storage costs at the terminals (5vi).

Constraints (6) define the energy content of the wood chips delivered at each power plant between the minimum demand and the maximum processing capacity. Constraints (7) state that the total flows of wood chips from piles at the roadside is at most the total availability. Constraints (8) account for the total number of chipping hours, that is upper bounded by the duration of the working shift plus the maximum allowed overtime, and lower bounded by the minimum working hours, if there is a chipper assigned to a pile. It is noteworthy that the minimum working hours in this constraint corresponds to the chippers usage cost. Below this number of hours, in principle it is more cost-efficient to conclude the work using overtime hours in the previous planning period. Complementary, constraints (9) set the number of overtime hours worked by each machinery/team, bounded by maximum allowed overtime. Constraints (10) establish the linkage between chippers' work hours and wood chips flows with origin in piles.

Constraints (11) and (12) balance the stocks per energy content at the terminals, taking into account the variation in energy content. Specifically, (11) set the amount of stock entering each terminal in each time period and moisture content class. Constraints (12) decrease the stock levels at the terminal in a given moisture content class by the amount of the outgoing flows. Which in turn are determined by the auxiliary parameter $\eta_{e_{1} e_{2} t_{1} t_{2}}^{o}$ that predicts the transition between moisture content classes, as explained in section 3.1. Constraints (13) bound the stock to the maximum capacity of the terminal. Constraints (14) bound the wood chips flows in a given period to the maximum transportation capacity available.

414

Constraints (15) to (18) deal with the assignment of chippers to piles and the space-time continuity of chipping operations. Specifically, Constraints (15) assure that a chipper is 
assigned to exactly one pile (or depot) in each time period. Constraints (16) and (17) account for the movement of the chipper between the piles (spatial continuity), where constraints (17) ensure that the chipper transportation cost for returning to the depot is considered at the end of the timeline. Constraints (18) ensure a flow conservation from $t$ to $t+1$ in each pile $p$. These constraints were adapted from the balanced network flow constraints in a single machine lot sizing problem in (Almada-Lobo et al. 2007). Specifically, the two summands in the first member of the equation relate to $t$ and cannot take value 1 simultaneously, i.e., either the chipper has already been in pile $p_{1}$ in period $t\left(x_{k p_{1} t}=1\right)$, or the chipper has moved to pile $p_{1}$ in the end of period $t$ $\left(\sum_{p_{2} \in P^{b}} Z_{k p_{2} p_{1} t}=1\right)$. The two summands of the second member of the equation related to $t+1$ are also mutually exclusive and are logically constrained by $t$. If $x_{k p_{1} t}=1$ then the chipper may continue in pile $p_{1}$ in $+1\left(x_{k p_{1}(t+1)}=1\right)$, or move to another pile $p_{2}$ at the end of period $t\left(\sum_{p_{2} \in P^{b}} Z_{k p_{1} p_{2} t}=1\right)$. If $\sum_{p_{2} \in P^{b}} Z_{k p_{2} p_{1} t}=1$, then the chipper will necessarily stay in pile $p_{1}$ in period $t+1$, as imposed by constraints (16). Constraints (19) assure that there is at the most one movement from each pile $\mathrm{p}$, along the entire time horizon.

Constraints (20) set the domain of the decision variables. These constraints take advantage of the previously defined parameters in order to eliminate non-admissible decision variables. For example, wood chips' flows from piles (or terminals) to power plants in a certain moisture content class are unfeasible if wood chips never reach those

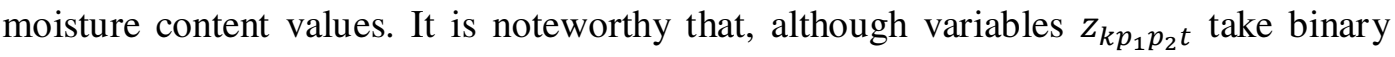
values, they may be linearized to improve the model performance.

\subsection{Model variations}

A simplification of the model is possible if the variation of the moisture content of the biomass at the terminals is not explicitly dealt in the model as a function of the storage age. In fact, there may be situations where the terminal is managed in a way that assures that the moisture content of the chips coming out of the terminal is fixed and previously determined in the beginning of the planning process. This may happen for example in large terminals, or when technical drying is used. In this case, the moisture content at the terminals in each time period is a parameter of the model, and is independent from the characteristics of the incoming flows that are set by the model.

Hence, the moisture content in each time period is a parameter varying with the terminal, which can be defined by the user in the beginning of the planning process. Model [M2] is significantly reduced in this aggregated approach since the set of classes of wood chips moisture content does not need to be considered and it is not necessary to keep track of the storage age of the wood chips batches. Thus, variables $f_{i j e t_{1} t_{2}}$ are replaced by $f_{i j t}$, representing the amount of wood chips transported from origin $i \in I$ to destination $j \in J$ in period $t \in T\left(\mathrm{~m}^{3}\right)$. While variables $S_{\text {oet }} t_{2}$ are replaced by $s_{o t}$, amount of wood chips stored at terminal $o \in O$ in the end of period $t \in T$. Similarly, parameters $\epsilon^{e}, \rho^{e}, \varphi_{e m}$, are replaced by $\epsilon_{i t}$ (energy content per volume unit of wood chips at origin $i \in I$ in period $t \in T(\mathrm{MWh} / \mathrm{m} 3)$ ), $\rho_{i t}$ (bulk density wood chips at origin $i \in I$ in period $t \in T(\mathrm{~kg} / \mathrm{m} 3)$ ), and $\varphi_{\text {imt }}$ (Price paid per volume unit of wood chips with origin in $i \in I$, delivered to 
power plant $m \in M$ in period $\left.t \in T\left(€ / \mathrm{m}^{3}\right)\right)$. Consequently, in model [M2] the objective 458 function is simplified (5b) and constraints (6), (7), (11) to (14) are replaced by (6b), (7b), 459 (11b) to (14b). New constraints (21) are needed to assure that the wood chips remain in 460 the terminal for at least one period.

461 Model [M2]:

$$
\begin{gathered}
\max F=\sum_{i \in I} \sum_{m \in M} \sum_{t \in T} \varphi_{i m t} \cdot f_{i m t}-\sum_{k \in K} \sum_{p \in P} \sum_{t \in T}\left[\omega_{k p} \cdot\left(h_{k p t}-h_{k p t}^{*}\right)+\omega_{k p}^{*} \cdot h_{k p t}^{*}\right]- \\
-\sum_{k \in K} \sum_{p \in P} \sum_{t \in T} C_{k}^{K} x_{k p t}-\sum_{j \in I} \sum_{j \in J} \sum_{t \in T} \tau_{i j t} \cdot f_{i j t}-\sum_{k \in K} \sum_{p_{1} \in P^{b}} \sum_{p_{2} \in P^{b}} \sum_{t \in T} \chi_{k} d_{p_{1} p_{2}} z_{k p_{1} p_{2} t}- \\
-\sum_{o \in O} \sum_{t \in T} \gamma_{o} \cdot s_{o t}
\end{gathered}
$$

Subject to: constraints (8), (9), (15), (16), (17), (18), (19),(20) and

$$
\begin{array}{cc}
d_{m} \leq \sum_{i \in I} \sum_{t \in T} \epsilon_{i t} f_{i m t} \leq C_{m}^{M} & \forall m \in M \\
\sum_{j \in J} \sum_{t \in T} f_{p j t} \leq a_{p} & \forall p \in P \\
\sum_{k \in K} h_{k p t_{2}} \cdot r_{k p}=\sum_{j \in J} \sum_{t_{1} \in T^{\emptyset}} f_{p j t_{1} t_{2}} & \forall p \in P, \forall t_{2} \in T \\
\sum_{p \in P} f_{p o t}=s_{o t} & \forall o \in O, \forall t \in T: t=0 \\
s_{o(t-1)}+\sum_{p \in P} f_{p o t}-\sum_{m \in M} f_{o m t}=s_{o t} & \forall o \in O, \forall t \in T \backslash\{0\} \\
\sum_{i \in I} \sum_{j \in J} \rho_{i t} \cdot f_{i j t} \leq C^{V} & \forall o \in O, \forall t \in T \\
\sum_{m \in M} f_{o m t} \leq C_{o(t-1)} & \forall t \in T
\end{array}
$$

Another possible model variation is a simplification of the movements of the chippers between piles (constraints 16) to improve model performance in case of instances of significant size. In fact, constraints (16) are computationally expensive due to the exponentially increasing number of $z_{k p_{1} p_{2} t}$ decision variables when the number of piles increases. The proposed simplification approach consists in outlining a set of $Q$ predefined geographical and non-overlapping neighborhoods for each pile $p-\psi_{p}=\psi_{p}^{0} \cup$ $\psi_{p}^{1} \cup \ldots \cup \psi_{p}^{Q-1}$ - given some distance radius criteria and re-set constraints (16) to (18) accordingly. For example, considering a certain pile $p$, where $Q=4$ : the first neighborhood $\left(\psi_{p}^{0}\right)$ could be composed by all piles within 20min distance of pile $p$, the second neighborhood $\left(\psi_{p}^{1}\right)$ by piles within $40 \mathrm{~min}$ distance (not including the ones already contained in $\psi_{p}^{0}$ ) and $\psi_{p}^{2}$ by all remaining piles. For each one of these neighborhoods we compute the average of the distances between pile $p$ and the locations in the 
476 incorporated in the model's objective function. Additionally, and due to the special

477 characteristics of this location, an additional neighborhood $\left(\psi_{p}^{3}\right)$ containing only the

478 depot is also set, so that this location can still be distinguished within the model.

479 Consequently, in the new model formulation [M3], decision variables $z_{k p_{1} p_{2} t}$ would be

480 replaced by variables $z_{k p q t}$, taking value 1 , if chipper $k \in K$ moves from pile $p \in P$ to 481 another location contained in neighborhood $\psi_{p}^{q}$ at the end of period $t \in T ; 0$, otherwise. 482 Constraints (16)-(18) would change to constraints (16b)-(18b) as described below.

Model [M3]:

Objective function (5) or (5b)

Subjected to: constraints (6) to (15), (20) and

$$
\begin{array}{cc}
z_{k p_{1} q(t-1)} \geq x_{k p_{1}(t-1)}+\sum_{p_{2} \in \psi_{p}^{q}} x_{k p_{2} t}-1 & \forall k \in K, \forall p_{1} \in P^{b}, \forall q, \forall t \in T \backslash\{0\} \\
z_{k p_{1} q(t-1)} \geq x_{k p_{1}(t-1)} & \forall k \in K, \forall p_{1} \in P, q=Q-1, t=|T| \\
x_{k p_{1} t} \geq x_{k p_{1}(t+1)}+\sum_{q \in Q} z_{k p_{1} q t} & \forall k \in K, \forall p_{1} \in P, \forall t \in T \\
\sum_{k \in K} \sum_{q \in Q} \sum_{t \in T} z_{k p_{1} q t} \leq 1 & \forall p_{1} \in P
\end{array}
$$

\section{Computational experiments}

The proposed model [M3] was applied to a case study inspired in a wood chips supplier company operating in Southern Finland. The model was implemented in the Gurobi 6.0.5 solver and was run in a $2.70 \mathrm{GHz} \mathrm{CPU}$ with capacity for 8 simultaneous processing threads. Model M3 was tested with three different planning horizons were tested: 1 month (40 half-day planning periods), 1.5 months (60 periods) and 2 months ( 80 periods). Then, the results for 1 month were analyzed in detail. An additional computational experience was conducted to compare the proposed planning approach under variable wood chips moisture content with the baseline situation that relies on empirical estimates for a fixed and known moisture content in the end of an obliged storage age.

\subsection{Case study}

The company manages their own chipping and transport operations, based on biomass supply contracts with the power plants. The company acquires the piles of forest residues that are byproducts of harvesting operations. The case under study encompasses 84 piles of forest residues of spruce, geographically distributed and ready to be chipped. Because a significant number of piles have very low availabilities and their distances to other piles are residual in some cases, a clustering procedure was implemented in order to reduce the problem size. After this procedure, a total number of 55 clusters of piles were considered, 
centroid of the circular cluster, computed with the GIS software based on the location of its piles; the movements of the chippers between the piles of the same cluster are neglected. The problem also contains 4 terminals and 12 power plants. The terminals are assumed empty in the beginning of the planning period. There are also 9 chippers available to do the work. Planning periods are halves of a day -3.5 hours, assumed to be the length of the regular chipping shift. The parameters of the model [M3] are summarized in Table 1.

This case considers 5 moisture content classes (class $\boldsymbol{e}_{\mathbf{1}} \in\left[\mathbf{1 5} \%, \mathbf{2 0} \%\left[\right.\right.$ to $\boldsymbol{e}_{\mathbf{5}} \in$ $514 \quad\left[50 \%, 60 \%[)\right.$. The bulk density for the average value of the class $e\left(\rho^{e}\right)\left(\mathrm{kg} / \mathrm{bulk} \mathrm{m}^{3}\right)$ is 2008, (Hartmann, 2007)). Similarly, the wood chips net caloric value for each class $\epsilon^{e}$ $\left(\mathrm{KWh} / \mathrm{m}^{3}\right)$ is computed with Equation 1 in respect to $\bar{e}^{e}$. The moisture content variation was obtained with the logistics function (equation 2) adjusted for the data set of (Holdrich and Hartmann 2006) as described in section 2.1. For each week of the planning period, moisture content was calculated, framed into its corresponding moisture content class and parameters $\beta_{\text {pet }}$ and $\eta_{e_{1} e_{2} t_{1} t_{2}}^{o}$ were set accordingly.

The other parameters of the model were inspired in a former biomass plan done by the company, including the location and availability of the piles; the location, demand and throughput of the plants, the location and capacity of the terminals; number and type of chippers, working hours and transportation capacity. Chipping and storage costs were inspired in the company business and perhaps below the range of the values found in the literature (e.g. (Francescato and Antonini 2008)). The transportation costs were computed with Equation 4, considering a unit transportation cost of $0.04 € / \mathrm{m} 3 / \mathrm{km}$. The distances between locations were computed by resorting to the national road dataset of Finland (http://www.liikennevirasto.fi/avoindata/digiroad\#.WPi-W1OGPfC). Prices of wood chips vary according to its moisture content and the power plant they are delivered to. These prices were estimated considering a fixed price of 20€/MWh ("Energy Prices" 2016). Only 7 of the 12 power plants accept wood chips regardless of their moisture content. Note that, although in this particular case the price is fixed, there is still an incentive for the model to opt for wood chips delivery of lower moisture content, as the price is fixed by energy content unit.

\section{$<$ table 1 here $>$}

In sum, the entire instance of 80 periods exhibits a total availability of approximately $19050 \mathrm{~m}^{3}$ of spruce wood chips in 55 macro-piles and the total demand in the 9 power plants is $26951 \mathrm{MWh}$ (corresponding to $16844 \mathrm{~m}^{3}$ of chips in the higher moisture class accepted by the power plants). Total available storage capacity is $52000 \mathrm{~m}^{3}$. The chipping capacity ranges between $119 \mathrm{~m}^{3}$ and $240 \mathrm{~m}^{3}$ per planning period and maximum transportation capacity per period is 600ton.

\subsection{Comparison of the model performance and results for 40,60 and 80 time periods}

Considering the three different planning horizons, the total demanded MWh increase proportionally to the number of planning periods. The wood chips availability also increases because at the beginning of the planning horizon a minority of the piles are available to be chipped, therefore, the longer the time horizon, the higher number of piles 
available (see Table 2).

The instance with 40 periods (17 macro-piles, demand of 13,475 MWh) results in a MIP problem with 2,529 binary variables, 49,462 continuous variables and 21,870 constraints, which is solved to optimality in approximately 48 minutes. The total profit of the biomass supplier is $196,161.00 €$. The profit gained at the end of 60 periods (45 macro-piles, demand of 20,213 MWh) increases to $266,150 €$. In this case, the M3 model has $38 \%$ more decision variables, $190 \%$ more constraints and takes 29 hours to solve the problem to optimality (with a gap of $0.01 \%$ ) (Table 3 ). For the instance with 80 periods (55 macropiles, demand of $26,951 \mathrm{MWh}$ ), the model size increases to 12,699 binary variables, 242,020 continuous variables and 187,440 constraints, which reaches the objective function value of $302,362 €$ with a gap of $3.38 \%$ after 36 hours. The analysis of the performance of the model suggests that this approach is adequate to solve problems to up to 40 periods ( 1 month) in a common computer, thus requiring more sophisticated solution approaches for larger problem instances.

$<$ tables 2 and 3 here $>$

In respect to the comparison of the model results, the number of chippers used along the planning horizon varies between 2 (40 periods) and 4 ( 80 periods) and the number of trucks is kept steady around 5 trucks per period. This happens because the chipper usage cost is considerably high and the optimal solution will favor using a chipper's capacity to its maximum instead of resorting to additional chippers. In these instances, terminals have excess capacity, so one terminal is sufficient in all test cases to accommodate all wood chips transshipment flows from macro-piles.

As time periods increase, it is also observable that the average storage age in piles and terminals tends to decrease. This fact is hardly justified by the model behavior and seems to be related with the characteristics of the instance under study. In fact, many piles become available (after harvesting) closer to the end on the planning horizon. Considering the 80 period's instance, the average period when piles become available is 43.4. Furthermore, the difference between piles' availability and power plants' demand decreases significantly and it forces the wood chips to be delivered to the plants sooner, thus spending less time in storage.

\subsection{Results of the test case of 40 periods}

In the 40 periods instance, the total profit from wood chips sales sums up 296284€, while total costs sum $100123 €$, corresponding to $62775 €$ of wood chips transportation costs, $5227 €$ of chipping costs, $19950 €$ of chipper usage costs, $11957 €$ of chipper transportation costs and $214 €$ of storage costs. Therefore, $76 \%$ of the costs relate to transportation and $24 \%$ of the costs to chipping. Considering that the chipping costs could have been underestimated in this case, it is possible to establish a rough threshold to total chipping costs considering the business breakeven point (costs equal to revenues). Assuming that all other cost items remain the same, the breakeven corresponds to total chipping cost of $74,503 €$. Thus the profit remains positive until the unit chipper utilization cost reaches $1035 €$, and the standard and overtime hourly costs reach $78 €$ and $117 €$, respectively.

Chipping operations: require 2 chippers and a total of 190 chipping hours to produce $7519 \mathrm{~m}^{3}$ of wood chips in 7 macro-piles (corresponding to 34 piles). The schedule of 
592 chipping and transportation roadside in macro-piles is presented in Figure 4a). For 593 example, in cluster 48 chipping starts in period 9 with chipper 4 and extends up to period 59413 , resulting in $710 \mathrm{~m} 3$ of wood chips, of which $691 \mathrm{~m}^{3}$ are transported to directly plant

59511 with moisture content $e_{3}$ [30-40\%], and $18 \mathrm{~m}^{3}$ are transported to terminal 12 , arriving 596 there also with moisture content class $e_{3}$. All the selected macro-piles require more than 597 one period to be fully chipped. This schedule confirms that temporal continuity 598 constraints are fully satisfied as chipping extends over consecutive periods.

599 A complementary view of the chipper's schedules shows the optimum sequence of 600 macro-piles for the selected chippers along the planning horizon (Figure 4b). For 601 example, chipper 4 starts working in period 9 in macro-pile 48, moves to macro-pile 30 602 in the end of period 13, then to macro-pile 31 in the end of period 32 and finally to macro603 pile 17 in the end of period 35. The total chipping hours are 94, including $7 \mathrm{~h}$ of overtime 604 work. The total chipping cost associated to the daily work of chipping 4 is $13972 €$. 605 Chipper 9 only serves macro-pile 6 and 45, working 95 hours, including 9 of overtime, 606 and costing $11615 €$. The schedule shows that spatial continuity constraints are fully 607 satisfied as the chipper moves to neighboring clusters after all the available amount of 608 forest residues in the pile is chipped and transported. It is noteworthy that chipping 609 operations only start after period 9. It is due to the fact that, as expected, the optimal 610 solution fulfills exactly all the demand at the plants and delays chipping as much as 611 possible, to take advantage of the decrease of moisture content while in storage at the 612 piles or terminals. Despite that fact, the chipping capacity in the last planning periods 613 remains sub-used due to the high daily chipper utilization costs.

614 The trade-off between the chipper utilization costs (350€/period) and the cost of regular 615 and overtime work (26.5 €/hour and $39.5 € /$ hour respectively) is shown in the model 616 results. For example, chipper 9 remains in macro-pile 45 for 16 periods and uses a total 617 of 57.6 hours or regular work and 8.5 hours of overtime, corresponding to a cost of 1526 $618 €$ for regular work and $335.75 €$ for overtime work, which is still lower than the additional 619 cost of $350 €$ for chipping the remaining amount in another period 17 without resorting 620 to overtime.

$<$ figure 4 here $>$

Transportation of wood chips/forest residues: the average transportation capacity used per period is 83.6 ton, corresponding to 5 trucks. Transportation starts in period 9 , which is also when chipping starts, thus confirming the consistency of the model in respect to the synchronization of these roadside operations. From period 9 up to period 17, the transportation flows are between 62 ton and 73 ton, corresponding to 3 trucks. Then, here is significant increase of the transportation flows until reaching a maximum of 174 ton (6 trucks) in period 20. From then up to period 31 the transportation flow fluctuates in a range that corresponds to the use of 4 trucks. Since then, 5 trucks are needed until the end of the planning horizon. The total transportation network is presented in in figure 5a).

Storage: only terminal 2 is used, because it is closest to a macro-pile and has one of the lowest utilization costs. Still the level of its utilization is very low. The maximum storage capacity used is $261 \mathrm{~m}^{3}$ in period 17, significantly below the terminal capacity $\left(4000 \mathrm{~m}^{3}\right)$. periods 17, 18 and 20, from macro-pile 56) with moisture content e3; and 4 outcoming flows (at period 11, 19, 20,22) with moisture content e2. The average storage age is 2 
periods, which is most likely a consequence of the parameters of the drying curve used in this case. For the forest residues stored in piles, the average storage age is 5 periods (Table $3)$.

The distribution of the chipping, transportation and storage amount along the time horizon is presented in figure 6a). Transportation and chipping are coincident, with the exception of the periods where there is transport from the piles to terminals and from the terminal to the plant. The piles are the main stocking location. There is an average of $2501 \mathrm{~m}^{3}$ stocked in the piles per period. The maximum of the stock occurs in period 17 when most of the piles used are already available but not yet chipped.

In respect to the profit increase due to the loss of moisture content during the time in storage, the $852 \mathrm{~m} 3$ stored in terminal 2 correspond to an increase of profit of $833 €$ that is the difference between $33572 €$ earned if delivered with the initial moisture content $\mathrm{e} 3$ and the realized profit of $34406 €$ with e 2 . The gain due to storage in the roadside piles is $2710 €$, corresponding to the decrease of moisture content from e4 to e 3 in macro piles 17 and 31 (Figure 6 b)). The total gain sums up $3543 €$ about $1,2 \%$ of the total profit. It is noteworthy that this value may be under-estimated since the decrease of moisture content in macro piles 28 and 48 not corresponded to a reduction of the moisture content class, consequently the gain is not quantified. This is a drawback of the discretization approach with the class length corresponds to $10 \%$ variation. When the initial moisture content is closer to the upper limit of the moisture class, the short storage age may not be enough to decrease to a lower class, while if the moisture content is closer to the lower limit of the class it will likelier decrease.

Demand fulfillment: As expected in this demand-driven problem, the amount supplied is equal to the maximum amount demanded by the plant, summing $14109 \mathrm{MWh}$ (figure $6 \mathrm{c})$ ). The majority of the plants was exclusively supplied with wood chips with moisture content e3 [30-40\%]. The exception of plant 11 that receives a small amount of $99 \mathrm{~m}^{3}$ of wood chips with higher moisture content due to the lack of wood with the lower moisture content. Another exception is plant 3 that receives a total of $426 \mathrm{~m}^{3}$ of wood chips with energy content e2 [20-30\%] (equivalent to $819 \mathrm{MWh}$ ). The justification is that plant 3 is the closest from terminal 2, therefore benefitting from the fact that the wood chipper have a longer drying age and were subjected to most favorable drying conditions (i.e. better drying curve) in that terminal than in other terminals or roadside piles.

$<$ figure 6 here $>$

\subsection{Comparison of the proposed planning approach under variable wood chips moisture with the baseline situation}

The baseline situation for supply planning corresponds to relying exclusively on empirical estimates for a fixed and known moisture content in the end of a fixed storage age that may vary according to each storage location. This is often the case when portable devices are not available or not frequently used to monitor the moisture content variation along the time spent in storage. In opposite, model [M3] used in this study explicitly handles the variation of moisture content along the variable time in storage, thus representing a change in the company current business practices that can help to reduce operational costs. 
681 In this study, we assumed a baseline corresponding to an initial moisture content in the 682 wood piles (after harvesting) of $48 \%$, unchangeable regardless the time remaining in 683 storage; and of $30 \%$ after 10 periods spent drying in a given terminal. The steps to

684 simulate the baseline include: 1) Adapt the data set to consider the empirical estimates of 685 moisture content of $48 \%$ in the wood piles, unchangeable regardless the time remaining 686 in storage; and of $30 \%$ after 10 periods spent drying in a given terminal; 2) Use [M2] to 687 compute values of the decision variables $x_{k p t}, h_{k p t}, h_{k p t}^{*}, z_{k p_{1} p_{2} t}, f_{i j t}, S_{o t}$ under those 688 assumptions; 3) Compute the $f_{i j e t_{1} t_{2}}$ equivalent to $f_{i j t}$ and the $s_{\text {oet }} t_{2}$ equivalent to $689 s_{o t}$ and then inject the values of the decision 690 variables $x_{k p t}, h_{k p t}, h_{k p t}^{*}, z_{k p_{1} p_{2} t}, f_{\text {ijet }_{1} t_{2}}, s_{\text {oet }} t_{2}$ in [M3] to compute the value of the 691 objective function.

692 The value of the objective function for the BAU obtained with this procedure is $186.371 €$. 693 This is 5,0\% less than the total profit obtained with our proposed approach that explicitly 694 handles the variation of moisture content along the variable time in storage (196.161€).

695 In fact, our approach shows that it is more cost-effective to leave the wood chips to dry 696 in the wood piles at the roadside. The flows to terminals are significantly reduced and the 697 chips remain there 2 periods, in average, instead of 10 as considered the BAU. 698 Consequently, transportation costs are 199.014€, 219\% higher than with the proposed 699 approach. The average transportation capacity used per period increases from 83.6 ton (5 700 trucks) to 316 ton (16 trucks). Similarly, storage costs in the BAU are 2172€, more than $701900 \%$ higher than with the proposed approach. This is because the BAU uses 3 terminals 702 instead of 1 , and it forces the material that goes to terminals to remain there for at least 70310 periods. The total transportation network for the 40 periods is presented in figure $5 \mathrm{~b}$ ). 704 By comparing both maps we can conclude that the optimal solution in the BAU favors 705 the visit to locations that are closer to each other because transportation costs are now 706 higher due to the increasing quantities that are stored in terminals. Roughly, chippers 707 perform chipping in the same piles, although macro-piles 31 and 17 are replaced in BAU 708 by macro-piles 23 and 29 in the chipping planning schedule.

709 <figure 5 here: map>

710

711

712

713

714

715

716

717

718

719

720

721

722

\section{Concluding remarks}

This paper presents a novel mathematical programming model for tactical biomass supply planning problem, in case of synchronized chipping and transportation at the roadside ("hot systems"), and explicitly considering the variation in chips energy content (or moisture content) over time in storage. It builds on previous research from Gunnarsson, Rönnqvist, and Lundgren 2004 and Flisberg, Frisk, and Rönnqvist 2012. 2 model variations were discussed. The first, does not account for moisture content classes, as it assumes that moisture content of the chips coming out from storage is a user-defined parameter, known at the beginning of the planning process. The second, is an simplified way to model the movement of the chipper between piles that considers geographic neighborhoods for each pile that at defined beforehand. This approach reduces the number of constraints, therefore improving the model performance for larger problem instances. The latter modelling approach is successfully used to solve to optimality within a 48 
minutes, problem instances with 17 macro-piles, 40 periods (half days), 4 terminals (for intermediate storage) and 12 power plants. 6 moisture content classes were considered, ranging from $30 \%$ to $55 \% .9$ chippers (with heterogeneous productivity) and 20 trucks (with homogenous capacity) were available. The results were presented in the form of a chipping-transportation schedule for each macro-pile/chipper and a flow map. Results suggest that a 5\% improvement in the supplier profit can be obtained with the proposed approach explicitly handles the variation of moisture content along the variable time in storage, when compared with a baseline situation that relies on empirical estimates for a fixed and known moisture content in the end of an obliged storage age.

Future work will seek alternative modelling approaches to solve larger instances that characterize real-life planning situations (e.g. 145 piles and up to 350 periods). For this purpose, a novel formulation will be developed, inspired in the generalized lotsizing and scheduling problem ( (Fleischmann and Meyr 1997). Alternative heuristic procedures may also be considered. Robust optimization or stochastic programming may be tested to address relevant uncertainty sources, both at the supply level (e.g. uncertainty in the moisture content values in each pile) and at the demand level (e.g. MWh demanded by each plant). In these cases, robust Future work may also seek for optimizing the daily routing and scheduling for each chipper and truck (at hourly level), taking into account the synchronization constraints (e.g. (Drexl 2013)).

\section{Acknowledgments}

This research has received funding from the European Union Seventh Framework Programme (FP7/2007-2013) under grant agreement number [604286]. This work is also financed by the ERDF - European Regional Development Fund through the Operational Programme for Competitiveness and Internationalisation - COMPETE 2020 Programme and by National Funds through the Portuguese funding agency, FCT - Fundação para a Ciência e a Tecnologia within project POCI-01-0145-FEDER-016733 (Easyflow). Further funding was obtained from the Project "NORTE-01-0145-FEDER-000020", financed by the North Portugal Regional Operational Programme (NORTE 2020), under the PORTUGAL 2020 Partnership Agreement, and through the European Regional Development Fund (ERDF).

\section{References}

Almada-Lobo, Bernardo, Diego Klabjan, Maria Antónia Carravilla, and José F. Oliveira. 2007. "Single Machine Multi-Product Capacitated Lot Sizing with Sequence-Dependent Setups." International Journal of Production Research 45 (20): 4873-94. doi:10.1080/00207540601094465.

Amorim, P., A. M. Costa, and B. Almada-Lobo. 2014. "Influence of Consumer Purchasing Behaviour on the Production Planning of Perishable Food." OR Spectrum 36 (3): 66992. doi:10.1007/s00291-013-0324-9.

Amorim, P., H. Meyr, C. Almeder, and B. Almada-Lobo. 2013. "Managing Perishability in Production-Distribution Planning: A Discussion and Review." Flexible Services and Manufacturing Journal 25 (3): 389-413. doi:10.1007/s10696-011-9122-3. 
Asikainen, Antti. 2010. "Simulation of Stump Crushing and Truck Transport of Chips." Scandinavian Journal of Forest Research 25 (3): 245-50. doi:10.1080/02827581.2010.488656.

Atashbar, N. Zandi, N. Labadie, and C. Prins. 2016. "Modeling and Optimization of Biomass Supply Chains: A Review and a Critical Look." IFAC-PapersOnLine, 8th IFAC Conference on Manufacturing Modelling, Management and Control MIM 2016Troyes, France, 28-30 June 2016, 49 (12): 604-15. doi:10.1016/j.ifacol.2016.07.742.

Casal, M. D., M. V. Gil, C. Pevida, F. Rubiera, and J. J. Pis. 2010. "Influence of Storage Time on the Quality and Combustion Behaviour of Pine Woodchips.” Energy 35 (7): 306671. doi:10.1016/j.energy.2010.03.048.

De Meyer, Annelies, Dirk Cattrysse, Jussi Rasinmäki, and Jos Van Orshoven. 2014. "Methods to Optimise the Design and Management of Biomass-for-Bioenergy Supply Chains: A Review." Renewable and Sustainable Energy Reviews 31: 657-670. doi:10.1016/j.rser.2013.12.036.

Drexl, Michael. 2013. "Applications of the Vehicle Routing Problem with Trailers and Transshipments.” European Journal of Operational Research 227 (2): 275-83. doi:10.1016/j.ejor.2012.12.015.

Dunnett, A., C. Adjiman, and N. Shah. 2007. "Biomass to Heat Supply Chains: Applications of Process Optimization.” Process Safety and Environmental Protection 85 (5): 419-429. doi:10.1205/psep07022.

"Energy Prices." 2016. Official Statistics of Finland. http://www.stat.fi/til/ehi/index_en.html. entrup, M. Lütke, H.-O. Günther, P. Van Beek, M. Grunow, and T. Seiler. 2005. "Mixed-Integer Linear Programming Approaches to Shelf-Life-Integrated Planning and Scheduling in Yoghurt Production.” International Journal of Production Research 43 (23): 50715100. doi:10.1080/00207540500161068.

Erber, Gernot, Christian Kanzian, and Karl Stampfer. 2012. "Predicting Moisture Content in a Pine Logwood Pile for Energy Purposes.” Silva Fennica 46 (4). doi:10.14214/sf.910.

Eriksson. 2016. Improving the Efficiency of Forest Fuel Supply Chains. Doctoral Thesis. Uppsala.

Eriksson, A., L. Eliasson, and R. Jirjis. 2014. "Simulation and Modeling of Wood Chip Container Logistics at Forest Landings.” BennetOY. http://www.bioenergyevents.fi/default.asp?sivuID=28594\&component=/_ACC/_Comp onents/ATLANTIS-digiStore/default_embed.asp\&ID=3827\&settings $=$.

Fleischmann, Bernhard, and Herbert Meyr. 1997. "The General Lotsizing and Scheduling Problem." Operations-Research-Spektrum 19 (1): 11-21. doi:10.1007/BF01539800.

Flisberg, P, M Frisk, and M Rönnqvist. 2012. "FuelOpt: A Decision Support System for Forest Fuel Logistics." Journal of the Operational Research Society 63 (11): 1600-1612. doi:10.1057/jors.2011.157.

Francescato, Valter, and Eliseo Antonini. 2008. "Wood Fuels Handbook.” AIEL. www.biomasstradecentres.eu.

Gold, Stefan, and Stefan Seuring. 2011. "Supply Chain and Logistics Issues of Bio-Energy Production.” Journal of Cleaner Production 19 (1): 32-42. doi:10.1016/j.jclepro.2010.08.009.

Gronalt, Manfred, and Peter Rauch. 2007. "Designing a Regional Forest Fuel Supply Network." Biomass and Bioenergy 31 (6): 393-402. doi:10.1016/j.biombioe.2007.01.007.

Gunnarsson, Helene, Mikael Rönnqvist, and Jan T Lundgren. 2004. "Supply Chain Modelling of Forest Fuel.” European Journal of Operational Research 158 (1): 103-123. doi:10.1016/S0377-2217(03)00354-0.

Hartmann, H. 2007. Handbuch Bioenergie-Kleinanlagen. Sonderpublikation des Bundesministeriums für Verbraucherschutz, Ernährung und Landwirtschaft und der Fachagentur Nachwachsende Roshstoff. http://www.tfz.bayern.de/mam/cms08/festbrennstoffe/dateien/handbuch_bioenergiekleinanlagen-komplett.pdf.

Hofmann, Nicolas, Theresa Mendel, Fabian Schulmeyer, Daniel Kuptz, Herbert Borchert, and Hans Hartmann. 2017. "Drying Effects and Dry Matter Losses during Seasonal Storage 
of Spruce Wood Chips under Practical Conditions.” Biomass and Bioenergy. Accessed April 10. doi:10.1016/j.biombioe.2017.03.022.

Holdrich, A., and H. Hartmann. 2006. "Rationelle Scheitholzbereitstellungsverfahren." Technologie-und Forderzentrum (TFZ). http://www.tfz.bayern.de/mam/cms08/festbrennstoffe/dateien/11_bericht.pdf.

Jaramillo, Fernando, and Murat Erkoc. 2017. "Minimizing Total Weighted Tardiness and Overtime Costs for Single Machine Preemptive Scheduling." Computers \& Industrial Engineering 107 (May): 109-19. doi:10.1016/j.cie.2017.03.012.

Kanzian, Christian, Franz Holzleitner, Karl Stampfer, and Sarah Ashton. 2009. "Regional Energy Wood Logistics - Optimizing Local Fuel Supply." Silva Fennica 43 (1). doi:10.14214/sf.464.

Karaesmen, Itir Z., Alan Scheller-Wolf, and Borga Deniz. 2011. "Managing Perishable and Aging Inventories: Review and Future Research Directions." In Planning Production and Inventories in the Extended Enterprise, edited by Karl G. Kempf, Pınar Keskinocak, and Reha Uzsoy, 393-436. International Series in Operations Research \& Management Science 151. Springer US. http://link.springer.com/chapter/10.1007/9781-4419-6485-4_15.

Karttunen, Kalle, Kari Väätäinen, Antti Asikainen, and Tapio Ranta. 2012. "The Operational Efficiency of Waterway Transport of Forest Chips on Finland's Lake Saimaa." Silva Fennica 46 (3). doi:10.14214/sf.49.

Krajnc. 2015. "Wood Fuels Handbook." FAO. www.fao.org/3/a-i4441e.pdf.

Lenz, Hannes, Christine Idler, Eberhard Hartung, and Ralf Pecenka. 2015. "Open-Air Storage of Fine and Coarse Wood Chips of Poplar from Short Rotation Coppice in Covered Piles." Biomass and Bioenergy 83 (December): 269-77. doi:10.1016/j.biombioe.2015.09.018.

Lopez. 2012. Drying of Woof-Forest Chips. Vol. XI. Technical Backgrounds for Advanced Techniques and Technologies in Biomass Production. biomassTradeCenter2 Project. http://www.biomasstradecentre2.eu/wood-biomass-production/technical-backgrounds/.

Nurmi, Juha. 1999. "The Storage of Logging Residue for Fuel." Biomass and Bioenergy 17 (1): 41-47. doi:10.1016/S0961-9534(99)00023-9.

Pettersson, M., and T. Nordfjell. 2007. "Fuel Quality Changes during Seasonal Storage of Compacted Logging Residues and Young Trees." Biomass and Bioenergy 31 (11-12): 782-92. doi:10.1016/j.biombioe.2007.01.009.

Shabani, Nazanin, Shaghaygh Akhtari, and Taraneh Sowlati. 2013. "Value Chain Optimization of Forest Biomass for Bioenergy Production: A Review." Renewable and Sustainable Energy Reviews 23 (July): 299-311. doi:10.1016/j.rser.2013.03.005.

Shabani, Nazanin, and Taraneh Sowlati. 2016. "A Hybrid Multi-Stage Stochastic ProgrammingRobust Optimization Model for Maximizing the Supply Chain of a Forest-Based Biomass Power Plant Considering Uncertainties." Journal of Cleaner Production 112, Part 4 (January): 3285-93. doi:10.1016/j.jclepro.2015.09.034.

Simpson, W., and J. Tschernitz. 1979. "Importance of Thichness Variation in Kiln Drying Red Oak Lumber.” Forest Products Laboratory, U.S. Forest Service. 


\section{P: piles $\{0,1\}$}

FR/Chips availability [bulk $\left.\mathrm{m}^{3}\right]$

FR/Chips initial moisture content [\%]

Variation of moisture content

Harvesting period

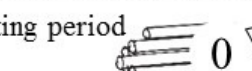

\section{K: chippers}

Utilisation cost [E/hour]

Shift and overtime [hours]

Productivity $\left[\mathrm{m}^{3} /\right.$ hour $]$
M: power plants $\{4,5\}$

Chips demand $[M W h]$

Price $[\epsilon / M W h]$

Throughput $\left[\mathrm{m}^{3}\right]$

Threshold of m. c. [\%]

Figure 1- Graphical representation of the biomass supply planning problem 
For a given chipper $k$ :

Time periods (e.g. days)

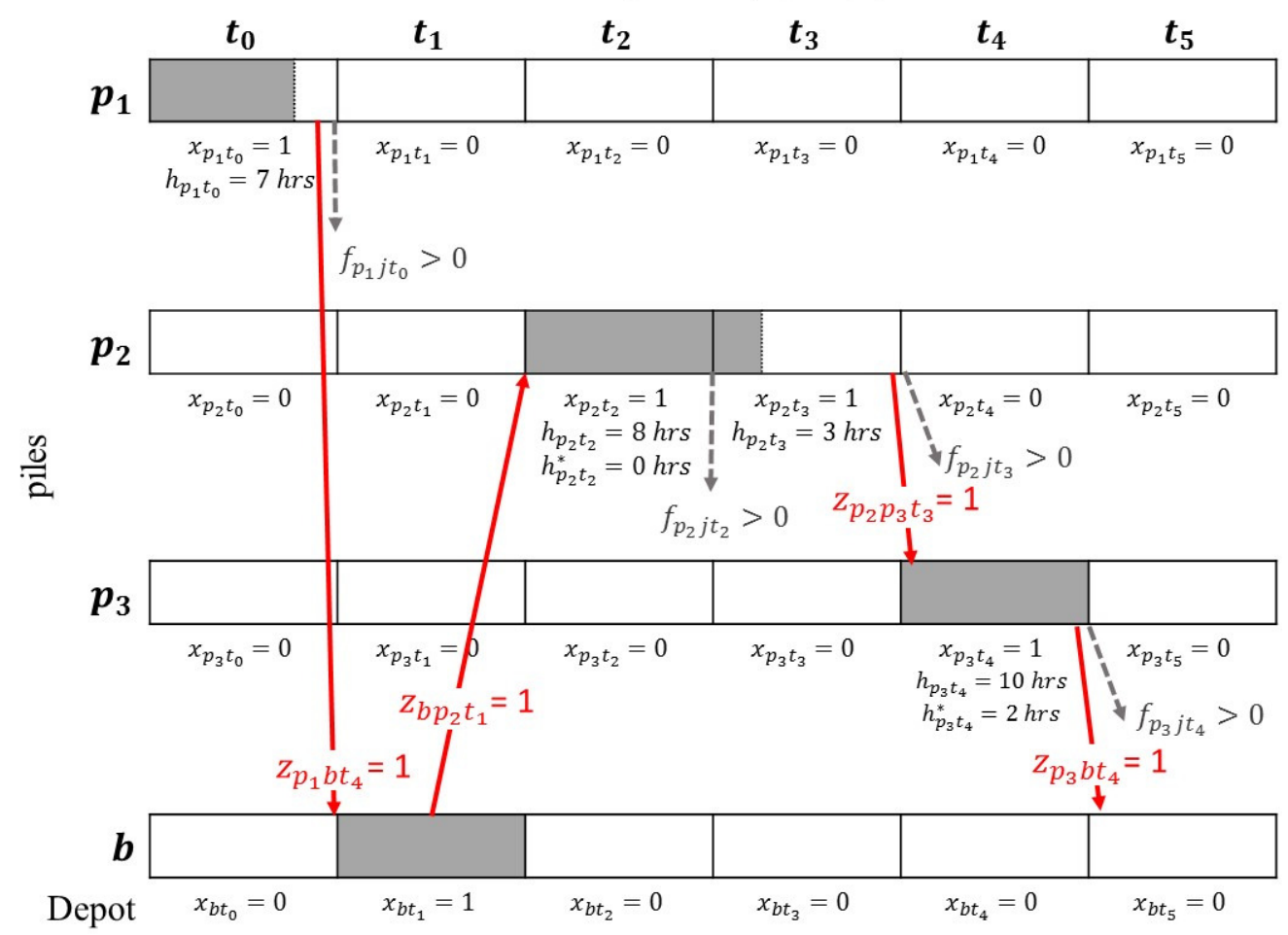

868 Figure 2 - Generic representation of an admissible solution for one chipper $k 3$ piles $\left\{p_{1}, p_{2}, p_{3}\right\}$,

8695 time periods $\left\{t_{1}, \ldots, t_{5}\right\}$ in respect to decision variables $x_{k p t}, h_{k p t}, h_{k p t}^{*}, z_{k p_{1} p_{2} t}$ and $f_{p j t}$. 870 For simplification purposes, the index $k$ was omitted in the figure. 


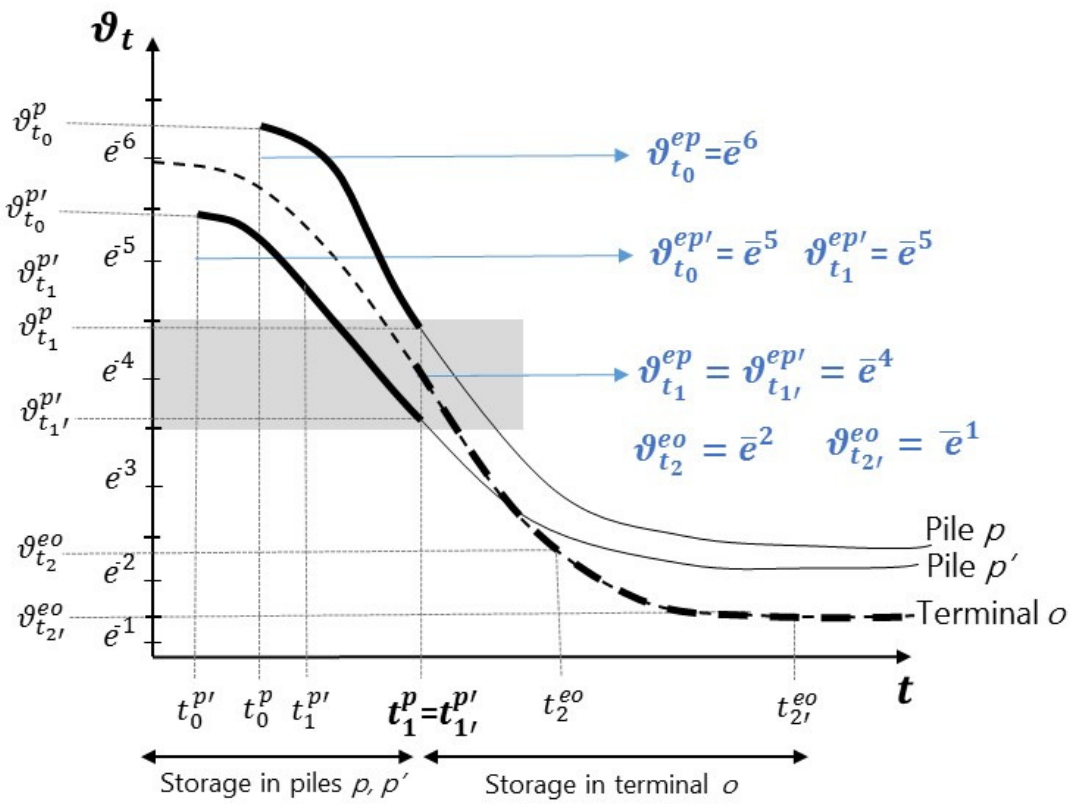

873 Figure 3 -Residues/wood chips drying process in the roadside pile and at the terminal Where: $\bar{e}^{e}$ : Average moisture content of class $e ; \vartheta_{t}^{p}, \vartheta_{t}^{p \prime}, \vartheta_{t}^{o}:$ Moisture content period $t$ of residues/chips located at the roadside pile $p, p^{\prime}$ or terminal $o$, respectively; $t_{0}^{p}, t_{0}^{p \prime}$ : Time period since which the roadside piles $p$ and $p$, are available, respectively; $t_{1}^{p}, t_{1}^{p^{\prime}}, t_{1}^{p^{\prime}}$ : Time period when residues/chips are transported from the piles $p$ or $p^{\prime} ; t_{2}^{e o}, t_{21}^{e o}$ : Time periods when chips that arrived to terminal o with initial moisture content e are transported from terminal o (to plant) 
881 Figure 4-Schedule chipping and transportation operations over the 40 periods in the 7 selected macro-piles with the 2 selected chippers

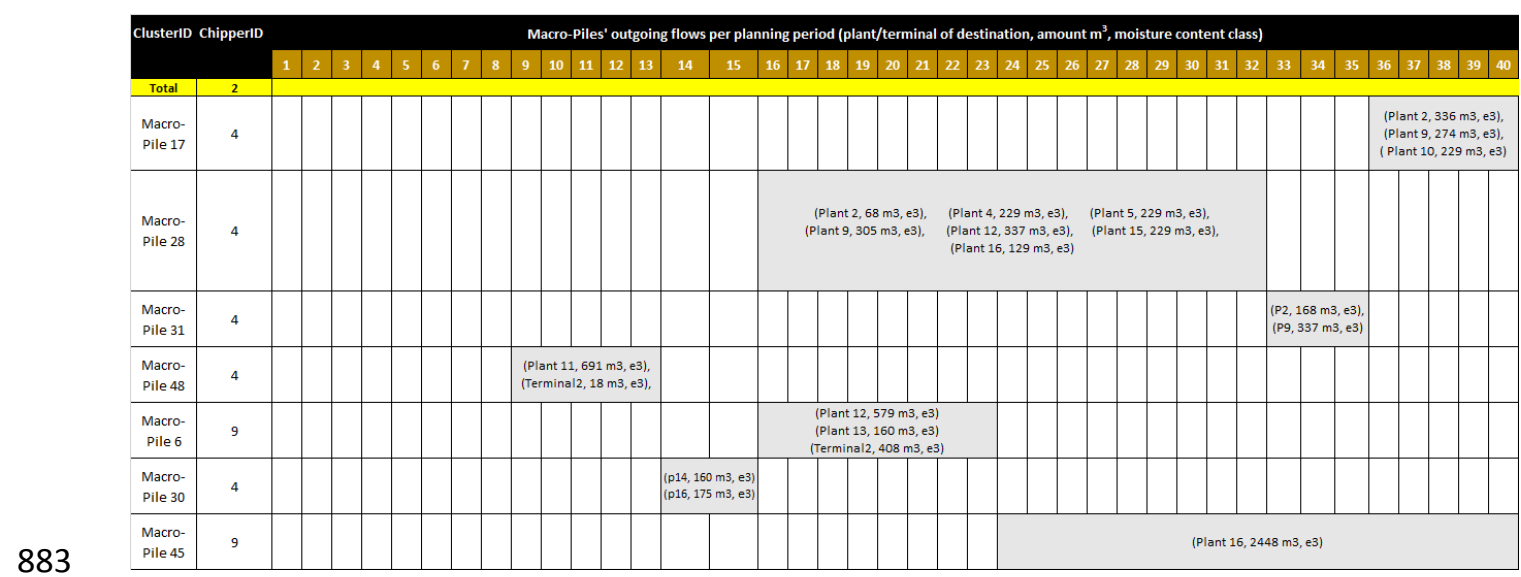

(a) Macro-piles schedule

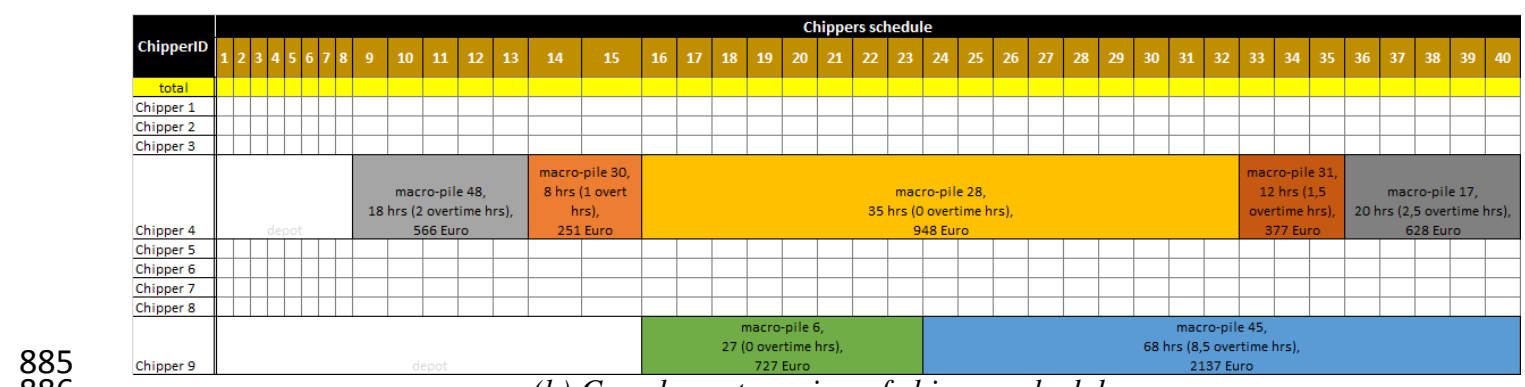

(b) Complementary view of chipper schedule 
889 890

Figure 5 - Transportation network between macro-piles, terminals and power plants for all the periods

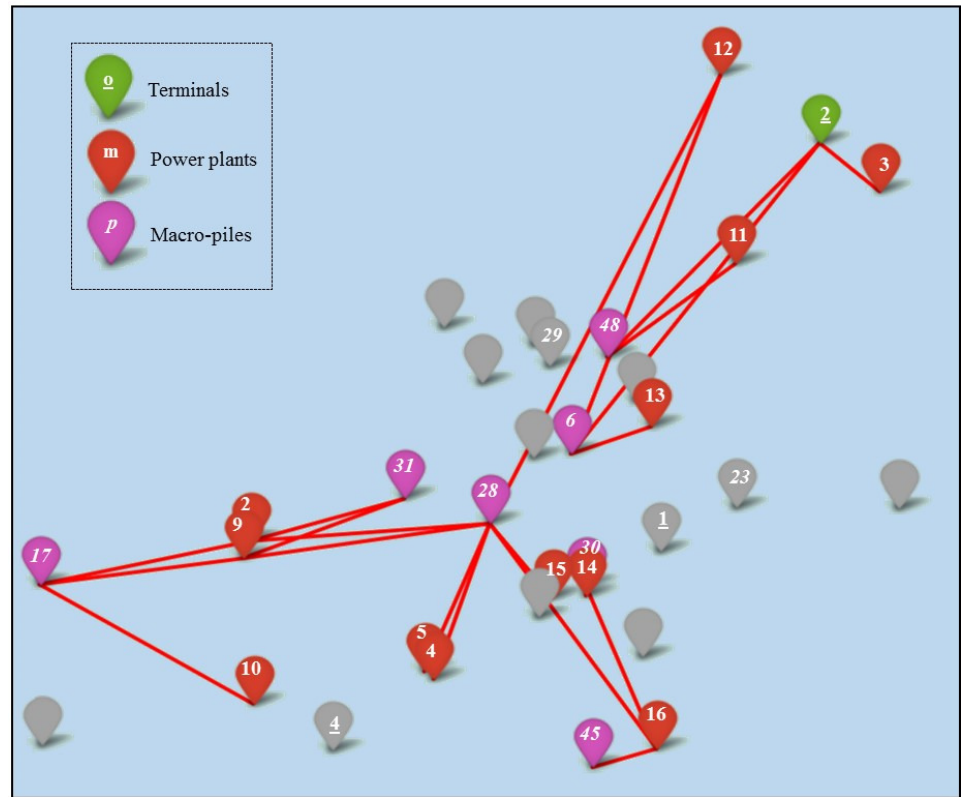

(a) Solution obtained with the new planning approach acknoledging the variation of the wood chips moisture content along the time spent in storage

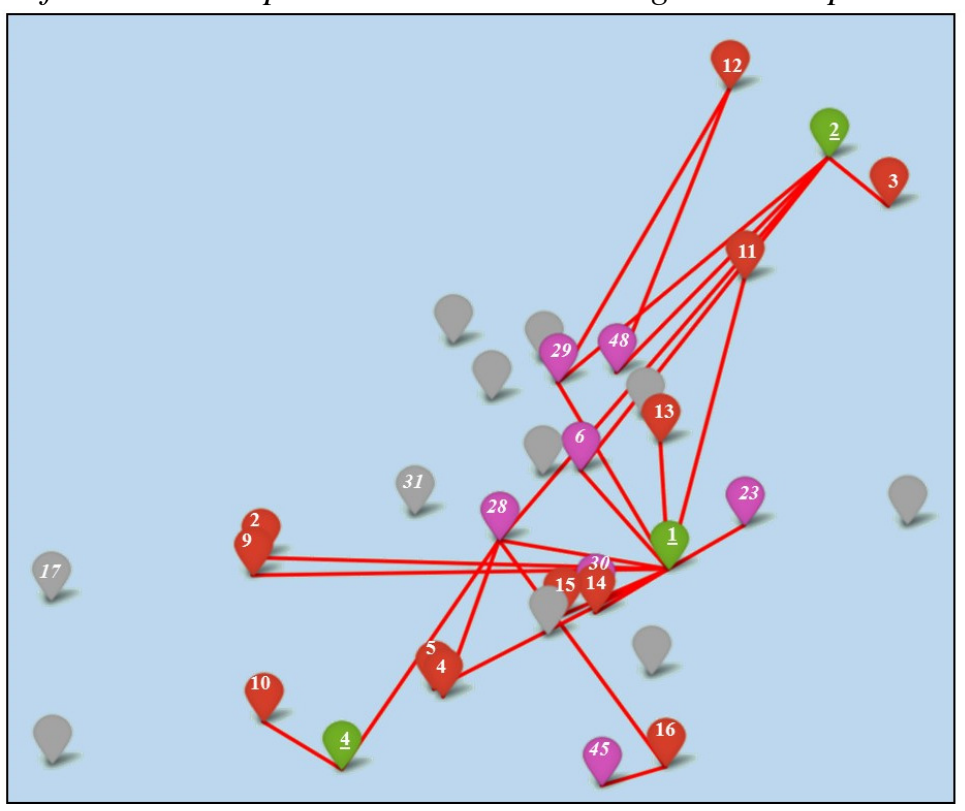

(b) Solution obtained for the baseline situation 


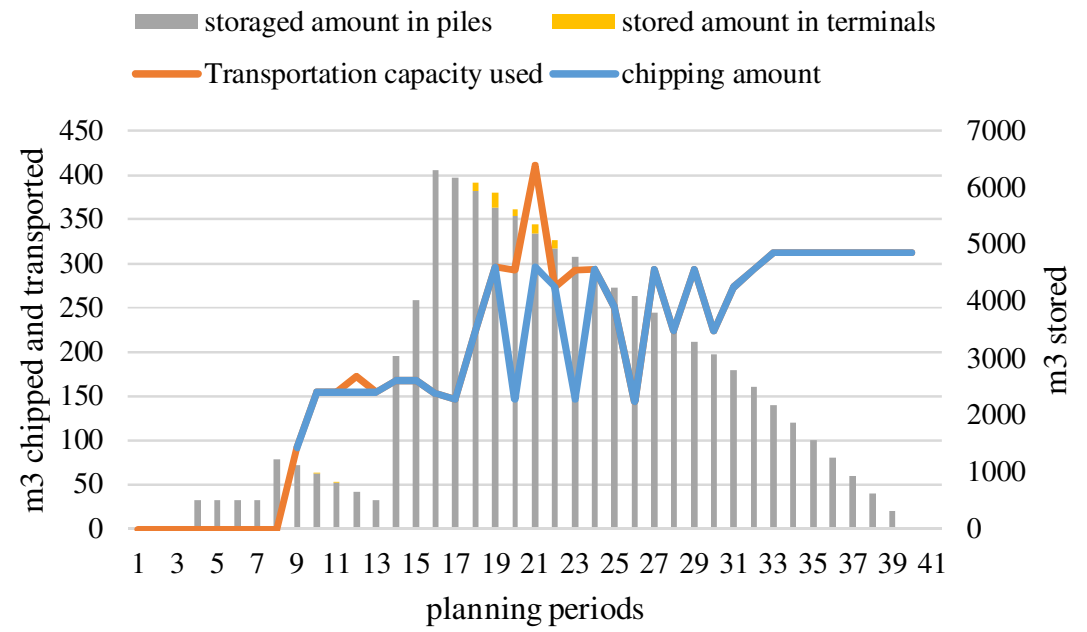

a) Chipping and transportation operations along the time horizon

Storage age and gains per storage location

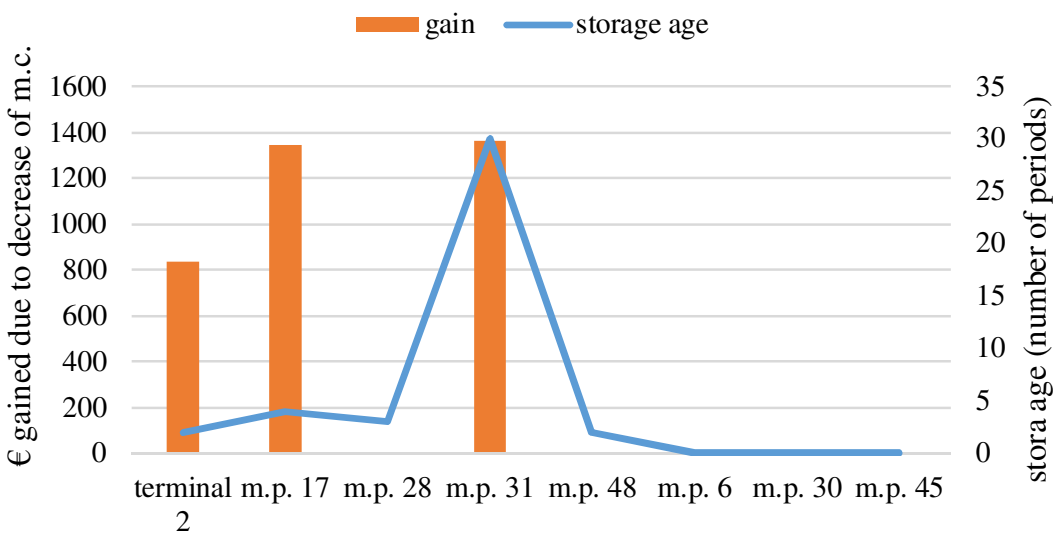

b) Storage age and gains per storage location

Plant supply ( $\mathrm{m}^{3}$ per moisture content class)

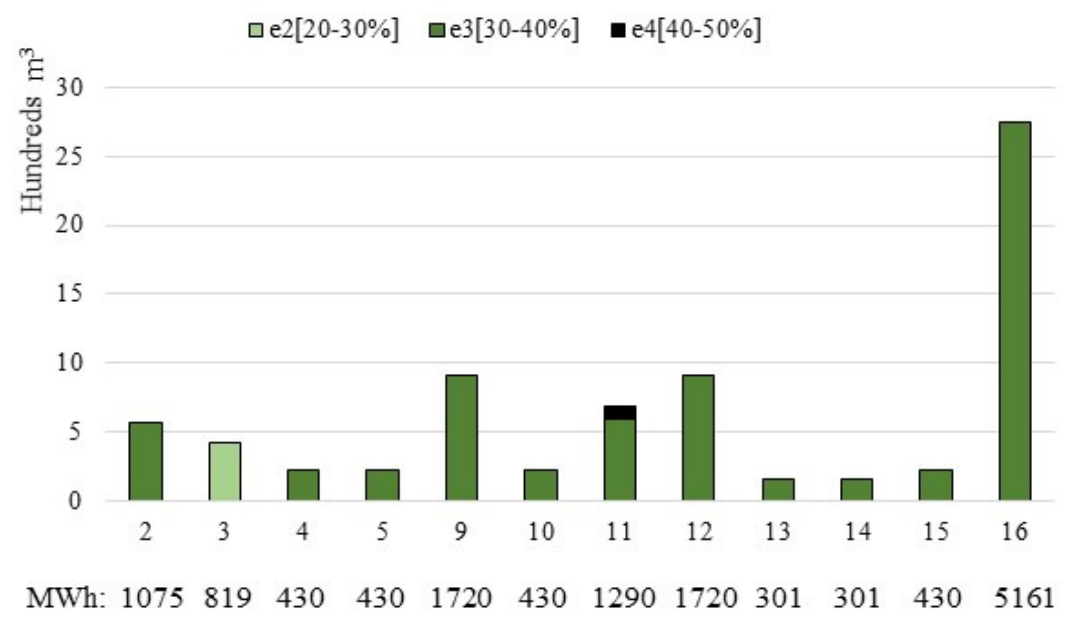

$1720-301-301-430-5161$ 
Table 1 - Values of the parameters of the model in the case study

\begin{tabular}{|c|c|}
\hline Sets / Parameter & Value \\
\hline $\begin{array}{l}\text { T: Planning periods } \\
\text { E: Classes of moisture content }\end{array}$ & $\begin{array}{l}\text { Varies between } 40 \text { and } 80 \text { (halves of a day) } \\
e_{1} \in\left[15,20\left[; e_{2} \in\left[20,30\left[; e_{3} \in\left[30,40\left[; e_{4} \in\left[40,50\left[; e_{5} \in\right.\right.\right.\right.\right.\right.\right.\right. \\
{[50,60[}\end{array}$ \\
\hline $\begin{array}{l}\rho^{\mathbf{e}}: \text { Bulk density for each class e } \\
\epsilon^{e}: \text { Wood chips net caloric value }\end{array}$ & $\begin{array}{l}\rho^{1}=354, \rho^{2}=424, \rho^{3}=483, \rho^{4}=572, \rho^{5}=632 \mathrm{~kg} / \mathrm{m}^{3} \\
\epsilon^{1}=1.92, \epsilon^{2}=1.87, \epsilon^{3}=1.8, \rho^{4}=1.73, \epsilon^{5}=1.47 \mathrm{MWh} / \mathrm{m}^{3}\end{array}$ \\
\hline $\begin{array}{l}\text { P: Macro-Piles } \\
a_{p}: \text { Chips availability } \\
\vartheta_{0}^{p}: \text { Initial moisture content } \\
t_{0}^{p}: \text { Time since when pile is available }\end{array}$ & $\begin{array}{l}\mathbf{5 5} \\
\text { Varies between } 10 \text { and } 2500 \text { bulk } \mathrm{m}^{3} \\
\text { Varies between } 30 \% \text { and } 50 \% \\
\text { Varies between period } 1 \text { and } 40\end{array}$ \\
\hline $\begin{array}{l}\text { M: Power plants (or mills) } \\
d_{m}: \text { Demand } \\
c_{m}^{M}: \text { Throughput } \\
\varphi_{e m}: \text { Price of wood chips }\end{array}$ & $\begin{array}{l}12 \\
\text { Varies between } 512 \text { and } 6144 \mathrm{MWh} \text { for the total planning horizon } \\
5 \% \text { more than the demand in each plant } \\
21 € / \mathrm{MWh}\end{array}$ \\
\hline $\begin{array}{l}\text { T: Terminals } \\
c_{o}^{O}: \text { Capacity } \\
\gamma_{o}: \text { Unit storage cost }\end{array}$ & $\begin{array}{l}4 \\
\text { Varies between } 4000 \text { and } 40000 \mathrm{~m}^{3} \\
\text { Varies between } 0,05 \text { and } 05 € / \mathrm{m}^{3}\end{array}$ \\
\hline K: Chippers & 3 \\
\hline $\begin{array}{l}r_{k p}: \text { productivity } \\
y_{k}^{m} ; y_{k} ; y_{k}^{*}: \text { Min, regular, max working } \\
\text { hours }\end{array}$ & $\begin{array}{l}\text { Varies according to chipper and pile, between } 34 \text { and } 48 \text { bulk } \\
\mathrm{m}^{3} / \text { hour } \\
0 ; 3,5 ; 0,5 \text { hours, equal for all chippers }\end{array}$ \\
\hline $\begin{array}{l}\omega_{k p} ; \omega_{k p}^{*}: \text { Regular, overtime hourly } \\
\text { chipping cost } \\
\chi_{k}: \text { Unit chipper transportation cost } \\
C_{k}^{K}: \text { Chipper usage cost }\end{array}$ & $\begin{array}{l}26,5 ; 39,5 € / \text { hour, equal to all piles } \\
1,2 € / \mathrm{km} \text {, equal for all chippers } \\
350 € / \text { period, equal for all chippers }\end{array}$ \\
\hline \multicolumn{2}{|l|}{ Wood fuel Transportation } \\
\hline $\begin{array}{l}c^{V}: \text { Truck transportation capacity } \\
N: \text { Number of available trucks } \\
\tau: \text { Unit transportation cost }\end{array}$ & $\begin{array}{l}30 \text { ton } \\
20 \\
0.04 € / \text { ton } / \mathrm{km}\end{array}$ \\
\hline
\end{tabular}


Table 2 - Computational results for model [M3], for 40 to 80 planning periods

\begin{tabular}{|c|c|c|c|c|c|c|c|c|c|}
\hline \multicolumn{3}{|c|}{ Instance Size } & \multicolumn{3}{c|}{ Model size } & \multicolumn{3}{c|}{ Computational time } \\
\hline $\boldsymbol{T}$ & $I$ & $\begin{array}{c}a \\
m^{3}\end{array}$ & $\begin{array}{c}D \\
M W h\left(m^{3}\right)\end{array}$ & \# bin. & \# cont. & \# const. & OF & $\begin{array}{c}\text { Runtime } \\
(\mathrm{s})\end{array}$ & $\begin{array}{c}\text { Gap } \\
\%\end{array}$ \\
\hline $\mathbf{4 0}$ & 17 & 16819 & $\begin{array}{c}13475 \\
(7018-11229)\end{array}$ & 2529 & 49462 & 21870 & 196161 & 2919 & 0.00 \\
\hline $\mathbf{6 0}$ & 45 & 18098 & $\begin{array}{c}20213 \\
(10527-16705)\end{array}$ & 6705 & 128451 & 63486 & 266150 & 107550 & 0.01 \\
\hline $\mathbf{8 0}$ & 55 & 19050 & $\begin{array}{c}26951 \\
(14036-22274)\end{array}$ & 12699 & 242020 & 122501 & 302362 & 129600 & 3.38 \\
\hline
\end{tabular}

905 T: N. time periods, I: N. macro-piles available up to the end of T; a: total availability of wood 906 chips up to $T\left(\mathrm{~m}^{3}\right)$; d: total demand up to $T$ (in $M W h$ and the range of corresponding $\mathrm{m}^{3}$ ); \# bin.: 907 number of binary variables; \# cont.: number of continuous variables; \# const.: Number of 908 constraints in the model; FO: value of the objective function $(\epsilon)$; Runtime until optimality proven 909 (sec.). 
Table 3 - Results for model M3, for 40, 60 and 80 planning periods

\begin{tabular}{|c|c|c|c|c|c|c|c|c|}
\hline $\boldsymbol{T}$ & $I^{\prime}$ & $\begin{array}{c}a^{\prime} \\
m^{3}\end{array}$ & $\begin{array}{c}d^{\prime} \\
M W h\left(m^{3}\right)\end{array}$ & $\mathrm{k}$ & $\begin{array}{c}\mathrm{h} \\
\text { hours }\end{array}$ & $\mathrm{s}$ & $\begin{array}{c}\mathrm{G} \\
\text { periods }\end{array}$ & $\mathrm{n}$ \\
\hline $\mathbf{4 0}$ & 7 & 7519 & $\begin{array}{c}14109 \\
(7519)\end{array}$ & 2 & 190 & 1 & 5.0 & 83.6 \\
\hline $\mathbf{6 0}$ & 22 & 11285 & $\begin{array}{c}21163 \\
(11285)\end{array}$ & 3 & 276 & 1 & 4.6 & 83.8 \\
\hline $\mathbf{8 0}$ & 42 & 14930 & $\begin{array}{c}28025 \\
(14930)\end{array}$ & 4 & 360 & 1 & 3.9 & 83.1 \\
\hline
\end{tabular}

913 T: N. time periods, I': N. macro-piles used; $a^{\prime}:$ total availability of wood chips effectively used $914\left(\mathrm{~m}^{3}\right) ; d^{\prime}$ : total demand fulfilled (MWh and $\left.\mathrm{m}^{3}\right) ; k$ : $N$. chippers; used; $h$ : total number of working 915 hours, including overtime work; $s$ : N. of terminals used; g: average storage age (periods); n: 916 average transportation capacity used per period (ton) 